\title{
Contribución efectiva al Impuesto Sobre la Renta en personas morales del régimen general*
}

\author{
Abigail Rodríguez Nava** \\ Carmelina Ruiz Alarcón***
}

\section{RESUMEN}

En esta investigación se analiza la contribución efectiva de las personas morales del régimen general al Impuesto Sobre la Renta en México, a partir de la comparación entre las utilidades netas y el impuesto pagado por las empresas con mayor capitalización en el país, es decir, las registradas en la Bolsa Mexicana de Valores. Asimismo, se propone una metodología para determinar la tasa efectiva de impuesto pagado, se cuantifica la magnitud de las deducciones autorizadas y se construyen escenarios de recaudación potencial. Los resultados de la investigación sugieren la fragilidad de la Ley del Impuesto Sobre la Renta en el sentido de que incluye una amplia gama de beneficios fiscales y deducciones autorizadas, sin que esté confirmado que estos beneficios generan compensaciones efectivas visibles en las principales variables macroeconómicas.

Palabras clave: impuesto al ingreso, personas morales, empresas mexicanas, ingreso gravable.

Clasificación JEL: E62, E64.

\begin{abstract}
This paper analyzes the effective contribution to the income tax by the Mexican companies. This is made from the comparison between net incomes and tax expenses of larger capitalization companies in Mexico, namely the companies listed on the Mexican Stock Market. A methodology for determining the effective rate of tax paid is also proposed, the magnitude of the deductions allowed is quantified, and the potential tax revenues scenarios are projected. Research also suggest the weakness of the Income Tax Law because it includes a wide range of tax benefits and tax deductions, but if these benefits have a positive impact on key macroeconomic variables is not confirmed yet.
\end{abstract}

Keywords: income taxes, legal persons, Mexican companies, taxable income. JEL classification: E62, E64.

\footnotetext{
* Fecha de recepción: 20/10/2011. Fecha de aprobación: 20/03/2013.

** Profesora del Departamento de Producción Económica de la Universidad Autónoma Metropolitana-Xochimilco. Correo electrónico: arnava@correo.xoc.uam.mx.

*** Profesora de la Facultad de Trabajo Social de la Universidad Veracruzana, campus Minatitlán. Correo electrónico: carmelinaruiz@yahoo.com.mx.
} 


\section{INTRODUCCIÓN}

Una de las relaciones constantes entre la sociedad y el Estado está dada por el ejercicio de las atribuciones recaudatorias de éste. Si bien, en principio, se trata de una relación unilateral en la que el Estado es el que exige la entrega de ciertas contribuciones económicas y los particulares son los que están obligados a ello, le subyace un carácter bilateral, de reciprocidad. En términos de la teoría del beneficio equivalente, la necesidad de la relación jurídico-tributaria se justifica en virtud de los servicios que el gobierno presta a los individuos como contrapartida a los impuestos que éstos pagan. Ningún particular accedería a contribuir al sostenimiento de un Estado que se negara a satisfacer las necesidades sociales, que en la actualidad van más allá de seguridad e infraestructura básica y adquieren un carácter más complejo al abarcar distintos ámbitos de la vida social y económica.

El artículo 31 de la Constitución Política de los Estados Unidos Mexicanos, en su fracción IV (Diario Oficial de la Federación, 1917), establece que es obligación de los mexicanos contribuir a los gastos públicos, tanto de la Federación como del estado y municipio en que residan, de la manera proporcional y equitativa que dispongan las leyes. Asimismo, de este precepto constitucional se derivan los principios en materia fiscal que debe observar toda ley secundaria (Carrasco, 1997; Arrioja, 2001). Tales principios son: 1) generalidad (aplicación a todas las personas que estén dentro de las hipótesis normativas que establezca la ley, sin excepción); 2) obligatoriedad (toda persona que se ubique dentro de las hipótesis de una ley fiscal del Estado mexicano adquiere la obligación de cubrir el tributo correspondiente); 3) vinculación con el gasto público (el Estado debe emplear todos los ingresos que recaude en la integración del presupuesto nacional); 4) legalidad (toda relación tributaria debe verificarse dentro de un marco legal que la establezca y la regule); 5) proporcionalidad y equidad. Estos últimos dos principios resultan particularmente importantes para los efectos del presente trabajo. El principio de proporcionalidad se define como aquel que

$[\ldots]$ en virtud del cual todas las leyes tributarias, por mandato constitucional, deben: establecer cuotas, tasa o tarifas progresivas que graven a los contribuyentes en función de su capacidad económica; afectar fiscalmente una parte justa y razonable de los ingresos, utilidades o rendimientos obtenidos por cada contribuyente individualmente considerado; y distribuir equilibradamente entre todas las fuentes de riqueza existentes y disponibles en el país, el impacto global de la carga tributaria, a fin de que la misma no sea soportada por una o varias fuentes en particular (Arrioja, 2001, p. 264). 
Por otra parte, conforme al principio de equidad, debe observarse

la igualdad ante la misma ley tributaria de todos los sujetos pasivos de un mismo tributo, los que en tales condiciones deben recibir tratamiento idéntico en lo concerniente a hipótesis de causación, acumulación de ingresos gravados, deducciones permitidas, plazos de pago, etc., debiendo variar únicamente las tarifas tributarias aplicables de acuerdo con la capacidad económica de cada contribuyente para respetar el principio de proporcionalidad (Mariano Azuela citado por Arrioja, 2001, p. 264).

Los debates en distintos ámbitos de la vida pública en México concluyen de manera coincidente en la necesidad de mejorar la estructura tributaria del país, dado que la recaudación no es suficiente para sufragar los gastos del gobierno, es inferior a la recaudación potencial y es inequitativa en términos absolutos. En esta reflexión, las disposiciones en materia del Impuesto Sobre la Renta (ISR) y la recaudación tributaria por este concepto deben ocupar un lugar de primer orden, pues se trata de la contribución que en la década reciente (de 2001 a 2010) ha representado, en promedio, $47.9 \%$ del total de los ingresos tributarios del país. Se trata de un impuesto complejo, característica asociada a las aspiraciones de progresividad, cuya base está integrada por la suma de las remuneraciones al trabajo, las rentas y las utilidades generadas por los activos físicos, y los intereses, dividendos y ganancias del capital devengados por los activos financieros.

Los estudios de carácter internacional dan cuenta de la amplia disparidad en los ingresos tributarios obtenidos. Por ejemplo, en un estudio presentado en 2009, la Organización para la Cooperación y el Desarrollo Económicos (OCDE) ubica a México como el país miembro con menor recaudación fiscal como proporción de su producto interno bruto (PIB), en un lista encabezada por Dinamarca (49.8\% de su PIB) y Suecia (48.2\%). Nuestro principal socio comercial, Estados Unidos, logra una recaudación equivalente a $28.3 \%$ de su PIB, y Argentina y Chile -países con un nivel de desarrollo similar al nuestro- de $27.3 \%$ y $21.5 \%$, respectivamente (OCDE, 2009, p. 115). ${ }^{1}$

Atacar los vacíos que hacen factible la evasión fiscal, identificar las disposiciones que se alejan de los principios de proporcionalidad y equidad, así como los procedimientos que propician ineficiencia en la recaudación fiscal, permitirían que el gravamen sobre los ingresos y las utilidades ampliara su parti-

\footnotetext{
${ }^{1}$ En la sección III.1 se muestran con detalle las cifras comparativas correspondientes.
} 
cipación como proporción del PIB y, consecuentemente, su peso en la recaudación tributaria del país. Precisamente, la eficiencia recaudatoria, tal como es reconocida por la Secretaría de Hacienda y Crédito Público (SHCP) y el Servicio de Administración Tributaria (SAT), se expresa en el crecimiento de la recaudación tributaria total como proporción del PIB. ${ }^{2}$ El problema de la evasión fiscal por concepto de ISR para personas físicas ha sido analizado por distintos autores (Revilla y Zamudio, 2001; Cantalá, Sempere y Sobarzo, 2005; Díaz y Mendoza, 2005; Samaniego, Endo, Mendoza y Zorrilla, 2006).

La investigación que se expone en este documento tuvo por objeto estimar las tasas efectivas de ISR pagadas por las personas morales en México, así como calcular la recaudación potencial por dicho impuesto. En México, la estimación de la base imponible es de tipo presuntivo, por lo que las personas físicas y asalariados, por lo general, sólo confirman esta estimación y realizan el pago de ISR de acuerdo a las tarifas (progresivas) oficiales publicadas en las Disposiciones de Vigencia Temporal de la Ley del Impuesto Sobre la Renta (LISR), ${ }^{3}$ mientras que las personas morales realizan aportaciones efectivas que son inferiores a la tasa establecida, lo que puede corroborarse a partir de indicadores que cuantifiquen la tasa de impuesto efectivamente pagada.

Debe subrayarse que esta investigación no exploró acciones como la evasión o elusión por parte de las personas morales, sino que se centró en la fragilidad de la LISR, en lo referente a la amplia gama de beneficios fiscales y deducciones que concede a éstas.

Un simple cálculo es revelador de esta situación: por ejemplo, en el año 2006, el gasto fiscal estimado por ISR de personas físicas fue de 145338.52 millones de pesos mexicanos y el correspondiente a personas morales fue de 217 822.74 millones de pesos; al relacionar estos datos con el padrón de contribuyentes, resulta que por deducciones autorizadas, a cada persona física se le otorgaron, en promedio, 6734 pesos y a cada persona moral, 314300 pesos. Es necesario, entonces, revisar en investigaciones futuras si los beneficios fiscales a las personas morales generan compensaciones efectivas visibles en las principales variables macroeconómicas.

\footnotetext{
${ }^{2}$ En México, el objetivo de la eficiencia recaudatoria fue definido como un crecimiento en la recaudación tributaria de $0.2 \%$ anual como proporción del PIB para el periodo 2007-2009 (SAT, 2010, p. 68).

${ }^{3}$ Esta hipótesis se sustenta en los trabajos sobre evasión fiscal de personas físicas, los cuales coinciden en señalar que la tasa de evasión de éstas es de aproximadamente $0.4 \%$ del PIB. Véase, por ejemplo, Díaz y Mendoza (2005, p. 52) o Samaniego, Endo, Mendoza y Zorrilla (2006, p. 6).
} 
La exposición se ha estructurado de la manera siguiente: en la sección I se presentan los antecedentes teóricos y empíricos de los estudios sobre el gravamen al ingreso de las empresas; en la segunda sección se muestra la evolución del ISR en México, con especial énfasis en la recaudación proveniente de las personas morales; en la tercera, se examinan las aportaciones a este impuesto por parte de las personas morales, se propone una metodología para determinar la tasa efectiva de gravamen pagado, se cuantifica la magnitud de las deducciones autorizadas y se construyen escenarios de recaudación potencial de ISR. Por último, se presentan las conclusiones de la investigación.

\section{ANTECEDENTES TEÓRICOS}

En el tema de gravamen al ingreso de las empresas, los trabajos de investigación teórica y su aplicación empírica están inclinados fuertemente al caso estadounidense y algunos son orientadores de la investigación que es necesaria desarrollar en el ámbito de México. Siguiendo a Hanlon y Heitzman (2010), para clasificar los distintos aportes pueden distinguirse cuatro áreas: a) análisis de la información procedente de los estados financieros para determinar el ingreso gravable; b) situación de evasión de impuestos por parte de las empresas; c) decisiones corporativas que afectan el pago de impuestos; d) vinculación entre impuestos y valor de mercado de las firmas; e) gravamen por ingresos en empresas multinacionales, y f) cambios legislativos y sus efectos en la recaudación. Por su vinculación con este trabajo, sólo se presenta una revisión de la literatura sobre las dos primeras áreas.

\section{Análisis de los estados financieros para determinar el ingreso gravable}

La principal contribución en este campo es el estudio de las diferencias halladas entre los ingresos reportados a los accionistas y los ingresos reportados a las autoridades hacendarias. Aunque esas diferencias presuponen, en algunos casos, situaciones de evasión de impuestos, el enfoque de las investigaciones se ha dirigido a estudiar las razones que explican estas discrepancias y el patrón que siguen las ganancias. La explicación central está asociada con la motivación económica de las firmas: evidentemente, a éstas les resulta conveniente reportar altos ingresos a los accionistas y reducidos a los organismos tributarios; varios estudios, entre ellos Cloyd, Pratt y Stock (1996) y Mills (1998), suponen que las empresas resuelven el dilema de decidir si reportar ingresos altos o escasos 
eligiendo la opción con el menor costo posible: un pago considerable de impuestos o alguna penalidad económica por parte de la autoridad tributaria.

Otros estudios han explorado desde diferentes perspectivas la vinculación entre la magnitud de las ganancias y los impuestos pagados; en Phillips, Pincus y Olhoft-Rego (2003), por ejemplo, se examina la administración de las ganancias a través de la utilización de los impuestos diferidos como medio para evitar la disminución de los beneficios, para protegerse de posibles pérdidas y con el fin de eludir la detección de ganancias futuras. Los impuestos diferidos también se analizan en Arcelus, Mitra y Srinivasan (2005); específicamente, se investiga cómo afectan la relación entre el rendimiento sobre inversión (la razón entre el ingreso neto de un año dado y el valor de los activos del año previo) y la $Q$ de Tobin (la razón entre el valor de mercado de la firma y el costo de reposición del capital) a la decisión de inversión de las empresas.

En Hanlon (2005), se analiza la persistencia de las ganancias y se muestra que en los casos con mayor diferencia entre los reportes de ingresos, la trayectoria de las ganancias es menos persistente en el tiempo. En Hanlon y Heitzman (2010), se resaltan tres elementos contables utilizados por los administradores de las empresas para tratar de manipular los resultados de ganancias e impuestos: las concesiones en la valuación de activos con impuestos diferidos, las reservas para impuestos contingentes y las ganancias que son reinvertidas permanentemente. ${ }^{4}$

Dos investigaciones interesantes, que sirven como base al presente trabajo, se hallan en Gupta y Newberry (2007) y Dyreng, Hanlon y Maydew (2008); aunque con distintas propuestas de clasificación del sector industrial estadounidense, ambos trabajos realizan estimaciones de la tasa efectiva del impuesto sobre el ingreso de las personas morales y coinciden en la amplia diferencia existente entre la tasa pagada y la tasa establecida en la legislación.

\footnotetext{
${ }^{4}$ Con la publicación de la Statement of Financial Accounting Standards No. 109 de Estados Unidos (Financial Accounting Standards Board, 1992), se realizaron cambios en la contabilidad de impuestos sobre ingresos. A partir de esa fecha, el gobierno estadounidense requirió a las empresas que estimaran los activos con impuestos diferidos, tanto para créditos fiscales como para posibles pérdidas; esta reglamentación permite evidentemente un amplio margen de discrecionalidad a las firmas. Véase Miller y Skinner (1998). En Accounting for Uncertainty in Income Taxes (FIN 48) (Financial Accounting Standards Board, 2006), se exigió que las firmas revelaran la magnitud de los beneficios no requeridos por impuestos; anteriormente sólo se requería que las firmas estimaran los posibles impuestos futuros resultantes de cambios es sus posiciones de activos y pasivos. En Blouin, Gleason, Mills y Sikes (2010) se muestran cifras de varios billones de dólares, para algunas empresas, correspondientes a este rubro. En Krull (2004), se muestra la discrecionalidad con que los administradores utilizan la partida de ganancias reinvertidas permanentemente.
} 


\section{Situación de la evasión de impuestos por parte de las empresas}

Las investigaciones sobre evasión de impuestos por parte de las empresas se encaminan a determinar cuáles son las metodologías adecuadas para su detección, qué criterios contables se usan para disminuir el pago de impuestos y qué determina la decisión de evadir, así como las consecuencias de ésta. Desai y Dharmapala (2009) estudian dos teorías que explican la evasión de las firmas; una de ellas, también examinada por Graham y Tucker (2006), señala que esta práctica es una extensión de otras actividades que buscan reducir los impuestos, como el uso de deuda; la otra teoría, también revisada por Desai y Dharmapala (2006), supone que al eludir impuestos se busca incrementar el valor de una empresa.

En Desai (2003), se analiza la divergencia entre los ingresos reportados a los accionistas y los reportados con fines impositivos; se muestra que en Estados Unidos esta brecha se ha ampliado desde los años noventa, y se sugieren como explicaciones la creciente utilización de argumentos como la depreciación y el origen extranjero de los beneficios para disminuir la base imponible y los cambios en la forma de compensación a los empleados, a quienes ahora las empresas les ofrecen opciones financieras sobre sus acciones, que son deducibles de los ingresos gravables. ${ }^{5}$ Otros trabajos que pretenden medir la brecha entre ingresos son los de Mills y Newberry (2001) y Plesko (2003).

Entre las investigaciones que examinan las consecuencias de la evasión de impuestos se encuentra la desarrollada por Hanlon y Slemrod (2009); estos autores encuentran que la asociación de una firma con prácticas de evasión de impuestos incide negativamente, aunque en escasa magnitud, sobre los rendimientos de sus acciones, mientras que las empresas no asociadas con esas prácticas presentan un menor impacto de este tipo. Chen y Chu (2005) desarrollaron un modelo teórico con el que intentan mostrar que si bien la evasión de impuestos por parte de una firma incrementa las ganancias retenidas en el corto plazo, esto sólo se logra incurriendo en el riesgo de que el ilícito sea detectado por las autoridades fiscales, así como la posibilidad de perder eficiencia en el interior de la empresa, debido a la incertidumbre generada en la compensación a los empleados, principalmente de los administradores. Hanlon y Heitzman (2010) sugieren ampliar las investigaciones sobre evasión de impuestos para examinar problemas del agente principal, los posibles efectos sobre fusiones y adquisiciones, y la

\footnotetext{
${ }^{5}$ Un dato relevante aportado en Desai (2003) es que entre 1996 y 2000 casi $27 \%$ del flujo de efectivo de las grandes empresas estadounidenses se produjo por el ejercicio de las opciones sobre las propias acciones.
} 
percepción y control del riesgo que supone el incumplimiento de las obligaciones fiscales.

\section{EVOLUCIÓN DEL IMPUESTO SOBRE LA RENTA (ISR) EN MÉXICO}

Algunos estudios han examinado la recaudación del ISR en México, pero se han centrado principalmente en la evasión. Entre estos trabajos se encuentran, por ejemplo, los de Antón (2005); Bergman, Carreón y Hernández (2005); Cantalá, Sempere y Sobarzo (2005); Díaz y Mendoza (2005), y Samaniego, Endo, Mendoza y Zorrilla (2006), pero, a pesar de su importancia, es difícil hallar estudios sistemáticos sobre el pago del ISR por parte de personas morales.

Cuadro 1. Ingresos tributarios del sector público en México

(como proporción del PIB)

\begin{tabular}{|c|c|c|c|c|c|c|c|c|}
\hline & Total & ISR & IETU & IVA & IEPS & ICE & IDE & Otros \\
\hline 1993 & $8.49 \%$ & $4.53 \%$ & - & $2.17 \%$ & $0.39 \%$ & $0.83 \%$ & - & $0.58 \%$ \\
1994 & $7.99 \%$ & $4.21 \%$ & - & $2.22 \%$ & $0.36 \%$ & $0.73 \%$ & - & $0.47 \%$ \\
1995 & $7.11 \%$ & $3.42 \%$ & - & $2.41 \%$ & $0.34 \%$ & $0.52 \%$ & - & $0.42 \%$ \\
1996 & $6.98 \%$ & $3.30 \%$ & - & $2.45 \%$ & $0.32 \%$ & $0.50 \%$ & - & $0.41 \%$ \\
1997 & $7.49 \%$ & $3.64 \%$ & - & $2.64 \%$ & $0.30 \%$ & $0.49 \%$ & - & $0.43 \%$ \\
1998 & $7.69 \%$ & $3.80 \%$ & - & $2.69 \%$ & $0.34 \%$ & $0.48 \%$ & - & $0.38 \%$ \\
1999 & $8.02 \%$ & $3.99 \%$ & - & $2.79 \%$ & $0.36 \%$ & $0.50 \%$ & - & $0.38 \%$ \\
2000 & $8.11 \%$ & $4.07 \%$ & - & $2.98 \%$ & $0.24 \%$ & $0.52 \%$ & - & $0.30 \%$ \\
2001 & $8.56 \%$ & $4.30 \%$ & - & $3.14 \%$ & $0.35 \%$ & $0.44 \%$ & - & $0.32 \%$ \\
2002 & $9.04 \%$ & $4.67 \%$ & - & $3.21 \%$ & $0.35 \%$ & $0.40 \%$ & - & $0.41 \%$ \\
2003 & $8.99 \%$ & $4.46 \%$ & - & $3.37 \%$ & $0.40 \%$ & $0.36 \%$ & - & $0.40 \%$ \\
2004 & $8.36 \%$ & $4.03 \%$ & - & $3.32 \%$ & $0.37 \%$ & $0.34 \%$ & - & $0.29 \%$ \\
2005 & $8.57 \%$ & $4.16 \%$ & - & $3.44 \%$ & $0.37 \%$ & $0.29 \%$ & - & $0.31 \%$ \\
2006 & $8.97 \%$ & $4.32 \%$ & - & $3.67 \%$ & $0.36 \%$ & $0.31 \%$ & - & $0.32 \%$ \\
2007 & $9.25 \%$ & $4.66 \%$ & - & $3.61 \%$ & $0.37 \%$ & $0.28 \%$ & - & $0.33 \%$ \\
2008 & $9.91 \%$ & $4.62 \%$ & $0.38 \%$ & $3.75 \%$ & $0.40 \%$ & $0.29 \%$ & $0.15 \%$ & $0.32 \%$ \\
2009 & $9.47 \%$ & $4.49 \%$ & $0.38 \%$ & $3.43 \%$ & $0.40 \%$ & $0.25 \%$ & $0.13 \%$ & $0.38 \%$ \\
2010 & $10.05 \%$ & $4.79 \%$ & $0.34 \%$ & $3.86 \%$ & $0.46 \%$ & $0.19 \%$ & $0.06 \%$ & $0.34 \%$ \\
\hline
\end{tabular}

Nota: ISR = Impuesto Sobre la Renta, IETU = Impuesto Empresarial a Tasa Única, IVA = Impuesto al Valor Agregado, IEPS = Impuesto Especial sobre Producción y Servicios, ICE = Impuestos al Comercio Exterior, IDE = Impuesto a los Depósitos en Efectivo.

Fuente: Elaboración propia con datos del Banco de México. 
Cuadro 2. Ingresos tributarios sobre el ingreso (individuos y empresas) (como proporción del PIB)

\begin{tabular}{|c|c|c|c|c|c|c|c|c|c|}
\hline & 2002 & 2003 & 2004 & 2005 & 2006 & 2007 & 2008 & 2009 & Promedio \\
\hline Aust & $.76 \%$ & $11.87 \%$ & $12.12 \%$ & $1.83 \%$ & $10.97 \%$ & $10.83 \%$ & $10.17 \%$ & - & $1.36 \%$ \\
\hline Austria & $.98 \%$ & $10.00 \%$ & $9.77 \%$ & $9.30 \%$ & $9.33 \%$ & $9.45 \%$ & $9.88 \%$ & $9.52 \%$ & $9.65 \%$ \\
\hline $\mathrm{ca}$ & $.19 \%$ & $3.93 \%$ & $13.76 \%$ & $13.78 \%$ & $13.19 \%$ & $13.03 \%$ & $13.45 \%$ & $12.97 \%$ & $13.54 \%$ \\
\hline anadá & $11.87 \%$ & $11.76 \%$ & $11.77 \%$ & $11.86 \%$ & $11.85 \%$ & $12.28 \%$ & $12.03 \%$ & $11.38 \%$ & $11.85 \%$ \\
\hline eca & $66 \%$ & $4.87 \%$ & $4.80 \%$ & $4.57 \%$ & $4.24 \%$ & $4.34 \%$ & $3.70 \%$ & $3.71 \%$ & $4.36 \%$ \\
\hline Dinamarca & $25.61 \%$ & $25.50 \%$ & $24.89 \%$ & $24.85 \%$ & $24.80 \%$ & $25.32 \%$ & $25.23 \%$ & $26.55 \%$ & $25.34 \%$ \\
\hline Finlar & $13.97 \%$ & $13.69 \%$ & $13.26 \%$ & $13.48 \%$ & $13.30 \%$ & $13.02 \%$ & $13.32 \%$ & $13.43 \%$ & $13.43 \%$ \\
\hline rancia & $7.51 \%$ & $7.54 \%$ & $7.39 \%$ & $7.92 \%$ & $7.73 \%$ & $7.41 \%$ & $7.52 \%$ & $7.26 \%$ & $7.54 \%$ \\
\hline Alem & $8.90 \%$ & $8.48 \%$ & $7.94 \%$ & $8.08 \%$ & $8.60 \%$ & $9.03 \%$ & $9.60 \%$ & $9.33 \%$ & $8.75 \%$ \\
\hline Grecia & $4.57 \%$ & $4.36 \%$ & $4.44 \%$ & $4.65 \%$ & $4.69 \%$ & $4.81 \%$ & $4.77 \%$ & $0.00 \%$ & $4.04 \%$ \\
\hline Hungría & $7.66 \%$ & $7.14 \%$ & $6.66 \%$ & $6.71 \%$ & $6.79 \%$ & $7.24 \%$ & $7.79 \%$ & $7.40 \%$ & $7.17 \%$ \\
\hline Islandia & $13.64 \%$ & $13.90 \%$ & $13.86 \%$ & $14.16 \%$ & $13.97 \%$ & $13.76 \%$ & $13.24 \%$ & $12.86 \%$ & $13.76 \%$ \\
\hline Israel & $10.00 \%$ & $8.86 \%$ & $7.97 \%$ & $7.72 \%$ & $7.85 \%$ & $8.08 \%$ & $7.33 \%$ & $6.32 \%$ & $8.02 \%$ \\
\hline Italia & $10.51 \%$ & $10.50 \%$ & $10.42 \%$ & $10.41 \%$ & $10.74 \%$ & $11.12 \%$ & $11.60 \%$ & $11.66 \%$ & $10.87 \%$ \\
\hline Japón & $4.82 \%$ & $4.50 \%$ & $4.67 \%$ & $5.01 \%$ & $5.16 \%$ & $5.55 \%$ & $5.62 \%$ & $5.37 \%$ & $5.09 \%$ \\
\hline Corea & $2.95 \%$ & $3.03 \%$ & $3.16 \%$ & $3.19 \%$ & $3.81 \%$ & $4.44 \%$ & $3.99 \%$ & $3.63 \%$ & $3.53 \%$ \\
\hline Países Bajos & $6.85 \%$ & $6.60 \%$ & $6.11 \%$ & $6.91 \%$ & $7.31 \%$ & $7.68 \%$ & $7.48 \%$ & - & $6.99 \%$ \\
\hline $\begin{array}{l}\text { Nuev } \\
\text { Zelar }\end{array}$ & $14.65 \%$ & $14.14 \%$ & $14.28 \%$ & $15.09 \%$ & $14.68 \%$ & $14.78 \%$ & $13.73 \%$ & $12.71 \%$ & $14.26 \%$ \\
\hline Noruega & $10.70 \%$ & $10.54 \%$ & $10.25 \%$ & $9.66 \%$ & $9.09 \%$ & $9.67 \%$ & $9.12 \%$ & $10.22 \%$ & $9.91 \%$ \\
\hline Polonia & $4.30 \%$ & $4.23 \%$ & $3.65 \%$ & $3.94 \%$ & $4.60 \%$ & $5.24 \%$ & $5.36 \%$ & - & $4.47 \%$ \\
\hline Portugal & $5.32 \%$ & $5.34 \%$ & $5.15 \%$ & $5.24 \%$ & $5.34 \%$ & $5.56 \%$ & $5.64 \%$ & - & $5.37 \%$ \\
\hline España & $6.54 \%$ & $6.35 \%$ & $6.14 \%$ & $6.42 \%$ & $6.82 \%$ & $7.40 \%$ & $7.14 \%$ & $6.67 \%$ & $6.69 \%$ \\
\hline Suecia & $14.67 \%$ & $15.16 \%$ & $15.30 \%$ & $15.44 \%$ & $15.42 \%$ & $14.64 \%$ & $13.81 \%$ & $13.48 \%$ & $14.74 \%$ \\
\hline Suiza & $10.26 \%$ & $10.03 \%$ & $10.03 \%$ & $10.41 \%$ & $10.45 \%$ & $9.14 \%$ & $9.12 \%$ & $9.78 \%$ & $9.90 \%$ \\
\hline Turquía & $4.34 \%$ & $4.08 \%$ & $3.58 \%$ & $3.57 \%$ & $3.82 \%$ & $4.09 \%$ & $4.00 \%$ & $4.03 \%$ & $3.94 \%$ \\
\hline & $10.35 \%$ & $9.90 \%$ & $9.95 \%$ & $10.40 \%$ & $10.56 \%$ & $10.86 \%$ & $10.73 \%$ & $10.44 \%$ & $10.40 \%$ \\
\hline $\begin{array}{l}\text { Estados } \\
\text { Unidos }\end{array}$ & $9.80 \%$ & $8.90 \%$ & $8.75 \%$ & $9.50 \%$ & $10.05 \%$ & $10.56 \%$ & $9.93 \%$ & $7.73 \%$ & $9.40 \%$ \\
\hline Promedio & $9.64 \%$ & $9.45 \%$ & $9.26 \%$ & $9.41 \%$ & $9.45 \%$ & $9.60 \%$ & $9.46 \%$ & $9.41 \%$ & \\
\hline
\end{tabular}

Fuente: OECD (s.f.). 
Las investigaciones realizadas coinciden en señalar que la principal fuente de ingresos tributarios para la hacienda pública mexicana es el ISR, pero su recaudación dista de lo deseable, sobre todo si se consideran las necesidades de gasto público. Al comparar la recaudación en México por ISR, como proporción del PIB (cuadro 1), con la obtenida en otros países por un gravamen similar (cuadro 2), se aprecia que, con excepción de la República Checa, Corea y Turquía, México tiene uno de los niveles de recaudación más bajos (menos de 5\%). En contraste, destacan algunos países que obtienen por este gravamen recursos importantes; por ejemplo, en 2011, Dinamarca obtuvo el equivalente a $26.55 \%$ de su PIB; Suecia, 13.48\%; Finlandia, 13.43\%; Bélgica, 12.97\%; Nueva Zelanda, $12.71 \%$; Italia, $11.66 \%$, y Noruega, $10.22 \%$.

\section{Estimación de las aportaciones al ISR por tipo de contribuyente}

Aunque en México no se publica sistemáticamente la aportación al ISR por tipo de contribuyente, de las cifras conocidas resulta que poco más de la mitad de la recaudación proviene de las personas morales, como se aprecian en el cuadro $3 .^{6}$

Un dato de interés es la proporción del PIB que representa el pago de este impuesto por parte de las empresas. En este aspecto, las estadísticas son muy contrastantes; por ejemplo, de la información de los cuadros 2 y 4 , se estima que durante 2009, en Dinamarca, la recaudación por gravar el ingreso de las empresas equivalió a 2.38\% de su PIB y la correspondiente a las personas físicas por el mismo concepto fue de $24.17 \%$ del PIB. En cambio, en Noruega, la aportación de las empresas representa $8.22 \%$ y la de las personas físicas sólo $2 \%$.

\footnotetext{
${ }^{6}$ El fundamento legal con el que se sustenta la no difusión de las contribuciones fiscales se encuentra en los artículos 18B y 27 del Código Fiscal de la Federación, que establecen: "Artículo 18B: La protección y defensa de los derechos e intereses de los contribuyentes en materia fiscal y administrativa, estará a cargo de la Procuraduría de la Defensa del Contribuyente, correspondiéndole la asesoría, representación y defensa de los contribuyentes que soliciten su intervención, en todo tipo de asuntos emitidos por autoridades administrativas y organismos federales descentralizados, así como, determinaciones de autoridades fiscales y de organismos fiscales autónomos de orden federal". Y: "Artículo 27: [...] El Servicio de Administración Tributaria llevará el Registro Federal de Contribuyentes basándose en los datos que las personas le proporcionen de conformidad con este artículo y en los que obtenga por cualquier otro medio; asimismo asignará la clave que corresponda a cada persona inscrita, quien deberá citarla en todo documento que presente ante las autoridades fiscales y jurisdiccionales, cuando en este último caso se trate de asuntos en que el Servicio de Administración Tributaria o la Secretaría de Hacienda y Crédito Público sea parte [...]" (Diario Oficial de la Federación, 1981).
} 
Cuadro 3. Aportaciones al ISR por tipo de contribuyente

\begin{tabular}{|c|c|c|c|c|c|c|c|}
\hline \multicolumn{4}{c}{$\begin{array}{c}\text { Número de } \\
\text { contribuyentes }\end{array}$} & \multicolumn{2}{c|}{ Millones de pesos corrientes } & \multicolumn{2}{c|}{ Porcentaje recaudación } \\
\cline { 2 - 8 } Año & $\begin{array}{c}\text { Personas } \\
\text { físicas }\end{array}$ & $\begin{array}{c}\text { Personas } \\
\text { morales }\end{array}$ & $\begin{array}{c}\text { Personas } \\
\text { físicas }\end{array}$ & $\begin{array}{c}\text { Personas } \\
\text { morales }\end{array}$ & Total & $\begin{array}{c}\text { Personas } \\
\text { físicas }\end{array}$ & $\begin{array}{c}\text { Personas } \\
\text { morales }\end{array}$ \\
\hline 2000 & 6500000 & 503000 & 159647.0 & 99107.2 & 258754.2 & $61.70 \%$ & $38.30 \%$ \\
2001 & 6728000 & 504000 & 126725.8 & 158797.3 & 285523.1 & $44.38 \%$ & $55.62 \%$ \\
2002 & 7020000 & 538000 & 152478.8 & 166838.1 & 319316.9 & $47.75 \%$ & $52.25 \%$ \\
2003 & 7215000 & 531000 & n.d. & n.d. & n.d. & n.d. & n.d. \\
2004 & 10016000 & 577000 & 182815.7 & 162401.8 & 345217.5 & $52.96 \%$ & $47.04 \%$ \\
2005 & 18147000 & 641000 & n.d. & n.d. & n.d. & n.d. & n.d. \\
2006 & 21580000 & 693000 & 208382.6 & 239717.2 & 448099.8 & $46.50 \%$ & $53.50 \%$ \\
2007 & n.d. & n.d. & 221874.2 & 305309.4 & 527183.6 & $42.09 \%$ & $57.91 \%$ \\
2008 & n.d. & n.d. & 265947.6 & 360561.0 & 626508.6 & $42.45 \%$ & $57.55 \%$ \\
\hline
\end{tabular}

Nota: Aunque a partir de 2004 se distingue entre personas físicas y asalariados activos, las cifras correspondientes a las primeras representan la suma de ambos.

n.d. = cifras no disponibles.

Fuente: Elaboración propia con base en $\operatorname{SHCP}(2007$, p. 90) y en SHCP $(2010$ a, p. 2).

Entre los países donde la aportación de personas físicas y empresas al impuesto sobre ingresos sí es equivalente, se encuentran Japón y Turquía. En México, la tendencia es a una contribución de las personas morales ligeramente mayor; por ejemplo, en 2007, de 4.6\% (como proporción del PIB) recaudado por ISR, $1.95 \%$ fue aportación de las personas físicas y $2.69 \%$, de las personas morales.

Conviene señalar que para gravar el ingreso en México, además del Impuesto Sobre la Renta, también se aplica el Impuesto Empresarial a Tasa Única (IETU) y el Impuesto a los Depósitos en Efectivo (IED). Existen dos mecanismos para integrar el ISR pagado por las empresas y por las personas físicas, de modo que se evite la doble tributación: la Cuenta de Utilidad Fiscal Neta (CUFIN) y la Cuenta de Capital de Aportación (CUCA). En el caso de los ingresos por dividendos, los accionistas obtienen un crédito que representa lo pagado en la empresa y que se usa como deducción al estimarse el pago como personas físicas. De acuerdo con estimaciones de la SHCP (2011), la introducción del IETU (en 2008) influyó indirectamente en una mayor recaudación por ISR. ${ }^{7}$

\footnotetext{
${ }^{7}$ Las diferencias esenciales entre el ISR y el IETU son las siguientes: en el caso del primero, la base para definir la contribución son las utilidades o la variación en la situación patrimonial; las deducciones autorizadas incluyen pagos de salarios, regalías, costos de ventas o de insumos, depreciación y pago de intereses; y además se usan como base los ingresos devengados o facturados.
} 
Cuadro 4. Ingresos tributarios sobre el ingreso de las empresas (como proporción del PIB)

\begin{tabular}{|c|c|c|c|c|c|c|c|c|c|}
\hline & 2002 & 2003 & 2004 & 2005 & 2006 & 2007 & 2008 & 2009 & Promedio \\
\hline Australia & $96 \%$ & $4.97 \%$ & $5.48 \%$ & $5.77 \%$ & $6.38 \%$ & $6.82 \%$ & & - & $75 \%$ \\
\hline$a$ & $0 \%$ & $17 \%$ & $26 \%$ & $2.22 \%$ & $19 \%$ & $.43 \%$ & $.45 \%$ & $1.71 \%$ & $2.20 \%$ \\
\hline ́lgica & $.04 \%$ & $2.87 \%$ & $.09 \%$ & $3.31 \%$ & $3.54 \%$ & $3.45 \%$ & $3.32 \%$ & $2.54 \%$ & $3.15 \%$ \\
\hline Inadá & $3.21 \%$ & $3.27 \%$ & $3.57 \%$ & $3.51 \%$ & $3.85 \%$ & $3.50 \%$ & $3.35 \%$ & $2.45 \%$ & $3.34 \%$ \\
\hline eca & $29 \%$ & $4.58 \%$ & $4.70 \%$ & $4.49 \%$ & $4.82 \%$ & $5.01 \%$ & $4.18 \%$ & $3.65 \%$ & $4.47 \%$ \\
\hline Dinamarca & $87 \%$ & $.90 \%$ & $3.16 \%$ & $3.92 \%$ & $4.34 \%$ & $3.77 \%$ & $3.41 \%$ & $2.38 \%$ & $3.34 \%$ \\
\hline Finlandia & $.17 \%$ & $3.41 \%$ & $3.52 \%$ & $3.34 \%$ & $3.39 \%$ & $3.87 \%$ & $3.50 \%$ & $2.04 \%$ & $3.41 \%$ \\
\hline & $2.86 \%$ & $2.48 \%$ & $2.76 \%$ & $2.41 \%$ & $2.97 \%$ & $2.97 \%$ & $2.91 \%$ & $1.44 \%$ & $2.60 \%$ \\
\hline & $1.01 \%$ & $1.26 \%$ & $1.57 \%$ & $1.72 \%$ & $2.10 \%$ & $2.19 \%$ & $1.89 \%$ & $1.33 \%$ & $1.63 \%$ \\
\hline Grec & $3.38 \%$ & $2.91 \%$ & $2.99 \%$ & $3.28 \%$ & $2.70 \%$ & $2.52 \%$ & $2.46 \%$ & $0.00 \%$ & $2.53 \%$ \\
\hline Hungría & $2.30 \%$ & $2.20 \%$ & $2.16 \%$ & $2.12 \%$ & $2.34 \%$ & $2.76 \%$ & $2.64 \%$ & $2.22 \%$ & $2.34 \%$ \\
\hline Islan & $0.88 \%$ & $1.24 \%$ & $1.03 \%$ & $1.98 \%$ & $2.40 \%$ & $2.49 \%$ & $1.93 \%$ & $1.12 \%$ & $1.63 \%$ \\
\hline Israel & $2.83 \%$ & $2.86 \%$ & $3.40 \%$ & $3.97 \%$ & $4.88 \%$ & $4.53 \%$ & $3.47 \%$ & $2.76 \%$ & $3.59 \%$ \\
\hline Italia & $3.11 \%$ & $2.77 \%$ & $2.82 \%$ & $2.79 \%$ & $3.41 \%$ & $3.81 \%$ & $3.71 \%$ & $3.08 \%$ & $3.19 \%$ \\
\hline Japón & $3.19 \%$ & $3.35 \%$ & $3.74 \%$ & $4.25 \%$ & $4.75 \%$ & $4.77 \%$ & $3.86 \%$ & $2.36 \%$ & $3.78 \%$ \\
\hline Corea & $2.96 \%$ & $3.67 \%$ & $3.32 \%$ & $3.82 \%$ & $3.58 \%$ & $4.00 \%$ & $4.23 \%$ & $3.69 \%$ & $3660 \%$ \\
\hline País & & $2.81 \%$ & $3.05 \%$ & $3.77 \%$ & & & & - & $3.24 \%$ \\
\hline Nue & $23 \%$ & $.59 \%$ & $5.39 \%$ & $6.16 \%$ & $5.69 \%$ & $4.97 \%$ & $4.43 \%$ & $3.34 \%$ & $4.85 \%$ \\
\hline Noruega & $8.14 \%$ & $7.98 \%$ & $9.85 \%$ & $11.76 \%$ & $12.95 \%$ & $11.42 \%$ & $12.51 \%$ & $8.22 \%$ & $10.35 \%$ \\
\hline Polonia & $2.04 \%$ & $1.80 \%$ & $2.22 \%$ & $2.48 \%$ & $2.40 \%$ & $2.75 \%$ & $2.71 \%$ & - & $2310 \%$ \\
\hline & $3.30 \%$ & $2.78 \%$ & $2.87 \%$ & $2.68 \%$ & $2.93 \%$ & $3.57 \%$ & $3.63 \%$ & - & $3.11 \%$ \\
\hline Esp & $18 \%$ & $.07 \%$ & $3.39 \%$ & $3.85 \%$ & $4.13 \%$ & $4.65 \%$ & $2.80 \%$ & $2.20 \%$ & $3.41 \%$ \\
\hline Suecia & $2.29 \%$ & $2.42 \%$ & $3.02 \%$ & $3.68 \%$ & $3.64 \%$ & $3.71 \%$ & $2.98 \%$ & $2.82 \%$ & $3.07 \%$ \\
\hline Suiza & $2.63 \%$ & $2.49 \%$ & $2.47 \%$ & $2.59 \%$ & $2.97 \%$ & $3.09 \%$ & $3.31 \%$ & $3.38 \%$ & $2.87 \%$ \\
\hline Turquía & $1.76 \%$ & $2.07 \%$ & $1.75 \%$ & $1.72 \%$ & $1.47 \%$ & $1.63 \%$ & $1.78 \%$ & $1.89 \%$ & $1.76 \%$ \\
\hline Reir & $2.82 \%$ & $2.70 \%$ & $2.83 \%$ & $3.33 \%$ & $3.94 \%$ & $3.41 \%$ & $3.55 \%$ & $2.76 \%$ & $3.17 \%$ \\
\hline Estados U & $1.71 \%$ & $2.09 \%$ & $2.47 \%$ & $3.15 \%$ & $3.41 \%$ & $3.05 \%$ & $1.84 \%$ & $2.06 \%$ & $2.47 \%$ \\
\hline Promedio & $3.06 \%$ & $3.03 \%$ & $3.29 \%$ & $3.63 \%$ & $3.87 \%$ & $3.87 \%$ & $3.55 \%$ & $2.58 \%$ & \\
\hline
\end{tabular}

Fuente: OECD (s.f.).

En cambio, en el IETU, la base de cálculo es la retribución a los factores de producción y permite como deducciones los salarios pagados, la compra de insumos y los gastos de inversión; y además la base es el ingreso recibido. Véase SHCP (2011). 
En el trabajo de Antón (2005), se realiza una estimación de las tasas efectivas pagadas por impuestos a partir de estadísticas de ingresos de la OCDE y del Sistema de Cuentas Nacionales de México; el análisis consiste en estimar las tasas efectivas sobre los impuestos al consumo y sobre los ingresos del capital y del trabajo, y en su metodología se comparan las magnitudes totales de impuestos pagados por ingresos y la base gravable. Entre los principales resultados para el periodo 1988-2002, se encuentra que la tasa efectiva del impuesto al consumo fluctúa entre $13 \%$ y $15 \%$, pero hay más variabilidad en el caso del impuesto al ingreso del capital, en el que se estiman tasas de entre $8 \%$ y $15 \%$.

En Bergman, Carreón y Hernández (2005), se estima la evasión del ISR por parte de personas morales con datos del Sistema de Cuentas Nacionales de México. La metodología de base consiste en estimar el excedente de explotación (que se define como la retribución al riesgo empresarial derivada de la actividad productiva) como el valor bruto de producción al que se descuenta el consumo intermedio, las remuneraciones a trabajadores, el consumo de capital fijo, las contribuciones imputadas sociales y los impuestos indirectos; una vez calculado esto, se obtiene la base gravable descontando las pérdidas de ejercicios fiscales anteriores, deducciones, donaciones y actividades exentas. Al aplicar a esta base gravable la tasa impositiva, los autores obtienen la recaudación potencial. Entre sus resultados destaca que el nivel de evasión representa de $32.6 \%$ a $39.5 \%$ de la recaudación potencial, es decir, entre $1.64 \%$ y $1.9 \%$, como proporción del PIB. También subrayan que de 2003 a 2004, las deducciones autorizadas representaron entre $4.1 \%$ y $4.2 \%$ del PIB.

\section{La legislación del ISR para personas morales}

La legislación que rige la aplicación del Impuesto Sobre la Renta en México la constituyen la Ley del Impuesto Sobre la Renta (LISR), el Reglamento de la Ley del Impuesto Sobre la Renta (RLISR), el Código Fiscal de la Federación (CFF) y el Reglamento del Código Fiscal de la Federación (RCFF). Con fines impositivos, la LISR clasifica a las personas morales, según su actividad principal, en las siguientes categorías: régimen general, régimen de consolidación fiscal, régimen simplificado, sociedades cooperativas de producción y régimen de personas morales con fines no lucrativos. ${ }^{8}$

\footnotetext{
${ }^{8}$ La definición de las personas morales se establece en la LISR; el régimen general (mercantil), en los artículos 1 a 4 y 8 ; el régimen de consolidación fiscal, en el artículo 64; el régimen simplificado, en los artículos 79 y 80; las sociedades cooperativas de producción, en el artículo 85A, y el
} 


\section{EL ISR EN PERSONAS MORALES DEL RÉGIMEN GENERAL}

Como ocurre en otros países, en México existen diferencias entre la contabilidad fiscal y la contabilidad financiera, originadas porque el propósito de cada una de ellas es distinto. En el caso de la contabilidad fiscal, el fin es determinar la base económica (renta o ingreso) que es objeto del impuesto, así como las tarifas y tasas de pago, las exenciones, los subsidios o estímulos fiscales, las compensaciones y las acreditaciones. ${ }^{9}$ Las cuotas efectivas de pago se establecen generalmente por el interés de estimular (o por el contrario, desincentivar) ciertas actividades productivas y en aras de impulsar el desarrollo macroeconómico. En cambio, la contabilidad financiera está dirigida principalmente a la evaluación de las actividades de una empresa, a través de su rentabilidad, liquidez, apalancamiento y eficiencia operativa.

En la primera parte de este trabajo se reseñaron las principales explicaciones acerca de las diferencias en contabilidad para el caso estadounidense: las concesiones en la valuación de activos con impuestos diferidos, las reservas para impuestos contingentes y las ganancias que son reinvertidas permanentemente (Hanlon y Heitzman, 2010), así como la depreciación de equipo, el origen extranjero de los beneficios y la compensación a empleados a través de opciones financieras sobre la acciones de las firmas (Desai, 2003).

En México, las autoridades hacendarias han realizado esfuerzos de conciliación entre el resultado fiscal y el contable (financiero). Como se mostrará en

régimen de personas morales con fines no lucrativos, en el artículo 95. Esta clasificación es distinta de la que se indica en la Ley General de Sociedades Mercantiles, que en su artículo 1 reconoce como sociedades mercantiles las siguientes: sociedad en nombre colectivo, sociedad en comandita simple, sociedad de responsabilidad limitada, sociedad anónima, sociedad en comandita por acciones y sociedad cooperativa. Una de los principales cambios en la LISR ha sido la tasa impositiva sobre los ingresos de las empresas: 2002, 35\%; 2003, 34\%; 2004, 33\%; 2005, 30\%; 2006, 29\%, y 2010, 30\%.

${ }^{9}$ Con precisión, en México no existen exenciones tributarias porque el artículo 28 de la Constitución Política de los Estados Unidos Mexicanos (Diario Oficial de la Federación, 1917) establece la prohibición de monopolios, prácticas monopólicas, estancos y exenciones de impuestos. En su lugar, existen beneficios fiscales, entre los que se cuentan los siguientes: 1) los subsidios, estímulos y deducciones autorizadas que son los beneficios establecidos en normas jurídicas, que aunque reconocen la realización de un hecho generador, conceden la dispensa parcial o total de la obligación tributaria; 2) la compensación de créditos que ocurre cuando dos sujetos son simultáneamente deudores uno del otro, por lo que sus obligaciones se extinguen hasta la concurrencia del valor correspondiente, y 3) los acreditamientos, que consisten en la disminución de una cantidad pagada respecto de otra para determinar la contribución (Venegas, 2011, pp. 124 y ss.). 
Cuadro 5. Gasto fiscal por ISR

\begin{tabular}{|c|c|c|c|c|c|c|c|c|c|c|}
\hline \multirow[t]{2}{*}{ Año } & \multicolumn{3}{|c|}{$\begin{array}{l}\text { Gasto fiscal } \\
\text { (millones de pesos a precios de } \\
2010 \text { ) }\end{array}$} & \multicolumn{3}{|c|}{ Proporción del PIB (\%) } & \multicolumn{4}{|c|}{ Tasas de crecimiento (\%) } \\
\hline & $\begin{array}{l}\text { ISR } \\
\text { total }\end{array}$ & $\begin{array}{l}\text { ISR } \\
\text { personas } \\
\text { físicas }\end{array}$ & $\begin{array}{l}\text { ISR } \\
\text { personas } \\
\text { morales }\end{array}$ & $\begin{array}{l}\text { ISR } \\
\text { total }\end{array}$ & $\begin{array}{l}\text { ISR } \\
\text { personas } \\
\text { físicas }\end{array}$ & $\begin{array}{c}\text { ISR } \\
\text { personas } \\
\text { morales }\end{array}$ & PIB & $\begin{array}{l}\text { ISR } \\
\text { total }\end{array}$ & $\begin{array}{c}\text { ISR } \\
\text { personas } \\
\text { físicas }\end{array}$ & $\begin{array}{c}\text { ISR } \\
\text { personas } \\
\text { morales }\end{array}$ \\
\hline 2002 & 243077.93 & 167458.13 & 75619.80 & 3.26 & 2.25 & 1.01 & & & & \\
\hline 2003 & 298171.77 & 156428.97 & 141742.80 & 3.95 & 2.07 & 1.88 & 1.35 & 22.67 & -6.59 & 87.44 \\
\hline 2004 & 300673.28 & 144286.07 & 156387.21 & 3.82 & 1.84 & 1.99 & 4.05 & 0.84 & -7.76 & 10.33 \\
\hline 2005 & 428658.07 & 155466.07 & 273191.99 & 5.28 & 1.92 & 3.37 & 3.21 & 42.57 & 7.75 & 74.69 \\
\hline 2006 & 363161.26 & 145338.52 & 217822.74 & 4.26 & 1.70 & 2.55 & 5.15 & -15.28 & -6.51 & -20.27 \\
\hline 2007 & 349783.40 & 181269.39 & 168514.01 & 3.97 & 2.06 & 1.91 & 3.26 & -3.68 & 24.72 & -22.64 \\
\hline 2008 & 284546.43 & 105359.42 & 179187.02 & 3.19 & 1.18 & 2.01 & 1.19 & -18.65 & -41.88 & 6.33 \\
\hline 2009 & 217379.75 & 58676.38 & 158703.38 & 2.60 & 0.70 & 1.90 & -6.12 & -23.60 & -44.31 & -11.43 \\
\hline 2010 & 210954.58 & 74669.87 & 136284.71 & 2.39 & 0.85 & 1.55 & 5.39 & -2.96 & 27.26 & -14.13 \\
\hline
\end{tabular}

Fuente: Elaboración propia con base en datos de SHCP (2010 b).

esta sección, la principal explicación de las diferencias no reside en situaciones de evasión o elusión de impuestos ${ }^{10}$ por parte de las empresas, sino en la considerable magnitud de las deducciones que son autorizadas cada año y que disminuyen sensiblemente el resultado fiscal. Una primera aproximación a este hecho se muestra en el cuadro 5, donde se observan tres aspectos: 1) El gasto fiscal ${ }^{11}$ por ISR es bastante considerable y su ausencia permitiría incrementar la recaudación

${ }^{10}$ El Servicio de Administración Tributaria define la evasión fiscal como "Toda acción u omisión parcial, o total, tendiente a eludir, reducir o retardar el cumplimiento de la obligación tributaria" (SHCP, 2010 b, p. 119). En términos jurídicos, la evasión o elusión fiscal se denota en alguno de los siguientes delitos por incumplimiento de los contribuyentes tipificados en el Código Fiscal de la Federación (Diario Oficial de la Federación, 1981): defraudación fiscal (Art. 108); asimilados a la defraudación fiscal (Art. 109), y relativos a declaraciones, contabilidad y documentación (Art. 111).

${ }^{11}$ La Secretaría de Hacienda y Crédito Público define los gastos fiscales como "los tratamientos de carácter impositivo que significan una disminución en la recaudación tributaria, y dan lugar a la aplicación de regímenes de excepción" (SAT, 2010). A partir de la Ley de Ingresos de la Federación para el Ejercicio Fiscal de 2007 (y en cada una de las leyes sucesivas que al decretarse abrogan la anterior), se establece en el artículo 28 la obligación de la SHCP de publicar el Presupuesto de Gastos Fiscales. 
promedio por este gravamen en más de 3\% del PIB. 2) Con excepción de los años 2002, 2003 y 2007, la mayor parte del gasto fiscal resulta de apoyos a personas morales. 3) El gasto fiscal no presenta el mismo desenvolvimiento del PIB, por ejemplo, en el año 2003 el crecimiento del PIB fue de $1.35 \%$, mientras que el gasto fiscal por ISR creció en $22.67 \%$; tampoco se verifica que el gasto fiscal incida en el PIB del año siguiente, por ejemplo, el gasto fiscal del año 2006 decreció en 15.28\%, pero el PIB del año 2007 aumentó en 3.26\%.

Las diferencias entre la contabilidad fiscal y financiera, así como la conciliación que propone la autoridad financiera en México, se explican a continuación. Las bases de la contabilidad fiscal para cuantificar los ingresos y el ISR causado en el ejercicio correspondiente de las personas morales del régimen general se establecen en el título II de la LISR (capítulos 10 a 92); los elementos básicos del cálculo son los ingresos acumulables, las deducciones autorizadas y las pérdidas fiscales. En el artículo 10 de la LISR se establece el procedimiento para calcular el ISR de las personas morales, que es el siguiente:

Las personas morales deberán calcular el Impuesto Sobre la Renta, aplicando al resultado fiscal obtenido en el ejercicio la tasa del $28 \%$.

El resultado fiscal del ejercicio se determinará como sigue:

I. Se obtendrá la utilidad fiscal disminuyendo de la totalidad de los ingresos acumulables obtenidos en el ejercicio, las deducciones autorizadas por este Título. Al resultado obtenido se le disminuirá, en su caso, la participación de los trabajadores en las utilidades de las empresas pagada en el ejercicio, en los términos del artículo 123 de la Constitución Política de los Estados Unidos Mexicanos.

II. A la utilidad fiscal del ejercicio se le disminuirán, en su caso, las pérdidas fiscales pendientes de aplicar de ejercicios anteriores (Diario Oficial de la Federación, 2002).

Los ingresos acumulados se definen en el artículo 17 de la LISR, mientras que las deducciones autorizadas se establecen en el artículo $29 .{ }^{12}$ Como se mues-

${ }^{12}$ En el artículo 20 de la LISR se establecen como otros ingresos acumulables los determinados por las autoridades fiscales, la ganancia derivada de la transmisión de propiedad de bienes por pago en especie, el beneficio por mejoras que pasan a poder del propietario, la ganancia por enajenación de activos (títulos, fusión y escisión), los pagos por recuperación de un crédito deducido por incobrable, la recuperación por seguros y fianzas, los ingresos por indemnización de seguro del hombre clave, las cantidades percibidas para gastos por cuenta de terceros, los ingresos moratorios, el ajuste anual por inflación y cantidades recibidas en efectivo mayores a seiscientos mil pe- 
tra en el cuadro A2 (anexo A), al resultado fiscal se le aplica la tasa de ISR correspondiente para calcular el monto de la contribución. Este resultado fiscal se obtiene a su vez de la utilidad fiscal que resulta de descontar las deducciones autorizadas del total de ingresos acumulables.

En términos contables, las Normas de Información Financiera ${ }^{13}$ establecen el procedimiento para integrar el balance general y el estado de resultados de una empresa. Para obtener la utilidad neta de la empresa, se determina primero la utilidad antes de impuestos agregando a la utilidad de operación el resultado integral de financiamiento y el resultado por partidas discontinuas; luego, a la utilidad antes de impuestos se le descuentan los pagos por ISR, IETU y PTU. El procedimiento para la conciliación de los registros contable y financiero definido por el Servicio de Administración Tributaria consiste en agregar a la utilidad neta (obtenida en el estado de resultados) los ingresos fiscales no contables y las deducciones contables no fiscales; al resultado se le descuentan las deducciones fiscales no contables y los ingresos contables no fiscales. Las partidas de los registros de la contabilidad fiscal, del estado de resultados y su conciliación se observan con detalle en el anexo A.

\section{Contribuciones al ISR de personas morales del régimen general}

En este apartado se desarrolla un análisis de las contribuciones efectivamente pagadas por ISR de las principales empresas en México; la base metodológica

sos. En el artículo 32 de la LISR se establecen las partidas que no son deducibles. De acuerdo con su artículo, las deducciones autorizadas para personas morales incluyen las devoluciones o bonificaciones, el costo de lo vendido, los gastos netos de descuentos, las bonificaciones o devoluciones, las inversiones, los créditos incobrables y las pérdidas fortuitas, las aportaciones para fondos de pensiones o jubilaciones, las cuotas pagadas al Instituto Mexicano del Seguro Social, los intereses devengados, el ajuste anual por inflación y los anticipos y rendimientos que paguen sociedades cooperativas de producción; en otros estudios podrían revisarse los montos de estas deducciones.

${ }^{13}$ En México, se han realizado considerables esfuerzos para la armonización de los registros contables financieros, principalmente a través del Consejo Mexicano para la Investigación de Normas de Información Financiera (CINIF), organismo creado en 2002 para renovar a la Comisión de Principios de Contabilidad (CPC) del Instituto Mexicano de Contadores Públicos (IMCP). Estos esfuerzos se concretan en las Normas de Información Financiera (NIF) y en su vinculación con las International Financial Reporting Standard (IFRS). Las IFRS (normas internacionales de información financiera) son normas establecidas por la International Accounting Standards Board (IASB), anteriormente International Accounting Standards Comittee (IASC). Otros esfuerzos de conciliación contable son los realizados en Estados Unidos, donde se pretende vincular las IFRS con sus Generally Accepted Accounting Principles (GAAP, principios de contabilidad generalmente aceptados, en español) establecidos por la Financial Accounting Standards Board (FASB). 
utilizada como referencia está constituida por el procedimiento establecido en la LISR para determinar el resultado fiscal, la metodología para el reporte de estados financieros establecido en las NIF y el procedimiento de conciliación fiscal y contable determinado por el SAT.

Dicho análisis abarca dos fases: 1) se examina la evolución del ISR efectivamente pagado por las empresas y se muestra su relación con el incremento de la utilidad neta, y 2) a partir de los estados financieros se obtiene el resultado fiscal, la utilidad o pérdida fiscal y se estima el monto de deducciones autorizadas. La principal base de datos utilizada es Economática, ${ }^{14}$ de donde se obtuvieron los estados financieros de las empresas cuyas acciones cotizan en la Bolsa Mexicana de Valores (BMV), excluyendo solamente a las firmas del sector financiero. El periodo de análisis se concentra entre 2000 y 2011, pero cuando existe información se reportan los resultados para el lapso 1993-2011.

Con el fin de resaltar diferencias entre las empresas y determinar si algún sector productivo o comercial exhibe mayor sensibilidad a los cambios en la legislación del ISR, se consideró conveniente adoptar la clasificación de la BMV, en sus distintos índices accionarios, aun cuando algunas compañías se ubiquen en más de uno. Se utilizaron los datos de las empresas que aparecen en los ocho siguientes índices: a) de los que corresponden a índices principales, IPC, INMEX, IPC LargeCap, IPC MidiCap e IPC SmallCap; b) de los índices sectoriales invertibles de rendimiento total, Telecom RT, y c) de los índices de actividad económica de rendimiento total, Construye RT y Comercio RT. Aunque existen otros índices disponibles construidos por la BMV, no se utilizaron porque la mayor parte de las empresas ya se encuentran representadas en los índices seleccionados; en su lugar, se emplearon los datos de las empresas emisoras que pertenecen a los siguientes sectores: industrial y de bienes y servicios de consumo no básico. En total, se obtuvieron diez grupos o muestras de empresas, que se detallan en el anexo B.

Debe subrayarse que la estimación de las tasas efectivas pagadas de ISR que se realiza en la sección III. 2 considera a las empresas que pertenecen a alguno de los índices de la BMV señalados. Se realizó una estimación para el año 2008 de la aportación al ISR total que representa el pago que realizan estas empresas. De acuerdo con el cuadro 3, las personas morales pagaron 360561 millones de pesos, de los cuales la suma de contribuciones por ISR de las empresas analizadas representa $34 \%$.

\footnotetext{
${ }^{14}$ Esta base, desarrollada por la empresa Econométrica, recopila información de más de mil compañías de las principales bolsas de América, desde su inicio de operaciones hasta la fecha.
} 


\section{a) Evolución del ISR efectivamente pagado}

De acuerdo con el procedimiento de conciliación fiscal y contable determinado por el SAT, la forma alternativa para calcular la utilidad o pérdida fiscal se basa en la utilidad o pérdida neta de la empresa, es decir, si de la utilidad o pérdida neta se descuentan las deducciones autorizadas, se obtiene la utilidad o pérdida fiscal. ${ }^{15}$ Este hecho conduce a suponer que la utilidad neta de las empresas debería evolucionar similarmente a la tributación por ISR, sin embargo, esto es dudoso.

Un ejemplo de la distinta evolución de las utilidades netas y las contribuciones al ISR de acuerdo con el sector de actividad económica se exhibe en la gráfica 1, donde se presenta el comportamiento de ambas variables entre las empresas que constituyen el IPC. La comparación indica que la brecha entre la utilidad neta y el monto total pagado por ISR se ha incrementado considerablemente, sobre todo a partir de 2004. Además resalta el incremento en la utilidad neta entre los años 2002 y 2007; esto se observa en casi todas los grupos de empresas examinados, con excepción de las muestras del IPC SmallCap y del sector de servicios y bienes de consumo no básico.

Gráfica 1. Evolución de las utilidades netas y del Impuesto Sobre la Renta de las empresas que constituyen el Índice de Precios y Cotizaciones de la Bolsa Mexicana de Valores

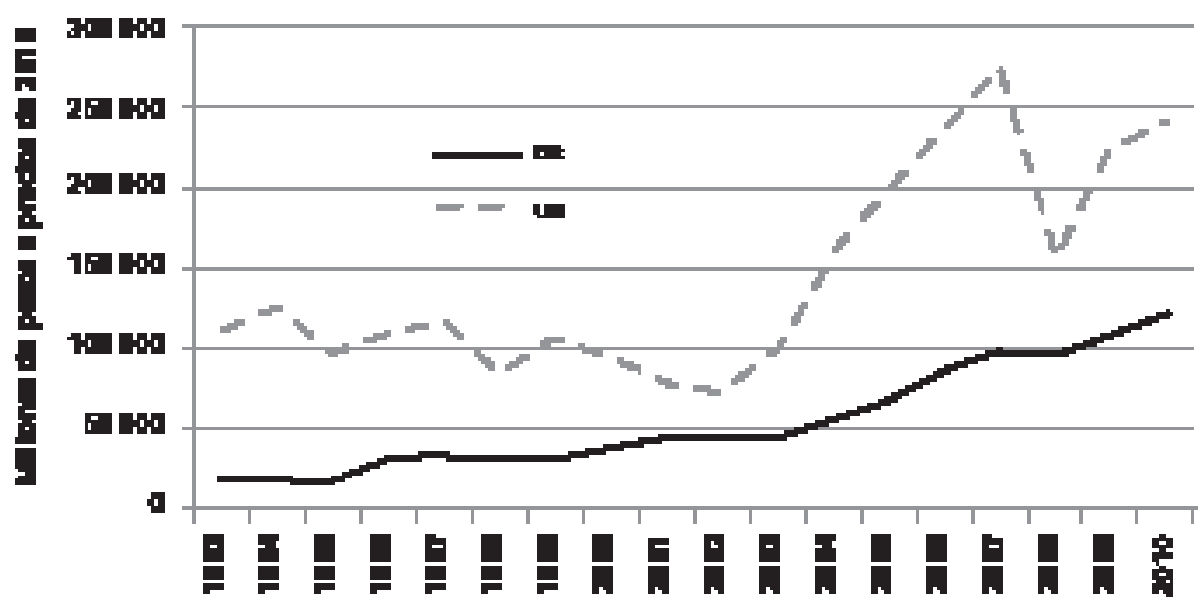

Nota: UN = utilidad neta.

Fuente: Elaboración propia.

\footnotetext{
${ }^{15}$ Véase cuadro A3 (anexo A).
} 


\section{b) Resultado fiscal y estimación de deducciones}

Con base en el procedimiento de conciliación fiscal y contable determinado por el SAT, se realizaron estimaciones del resultado fiscal $(R F)$, la utilidad o pérdida fiscal $(U F)$ y las deducciones autorizadas $(D A)$ para cada una de las empresas de los grupos considerados en el análisis; esto se hizo utilizando los estados de resultados trimestrales de cada empresa, desde su fecha de registro en la BMV hasta el primer trimestre de 2011.

Se realizaron tres estimaciones alternativas del resultado fiscal (base de la determinación del ISR causado en el ejercicio), que son las siguientes:

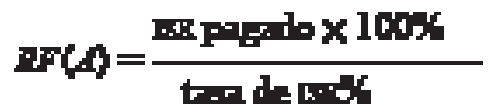

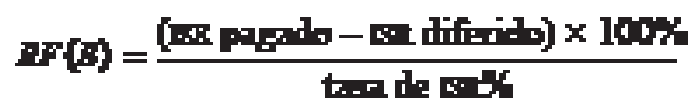

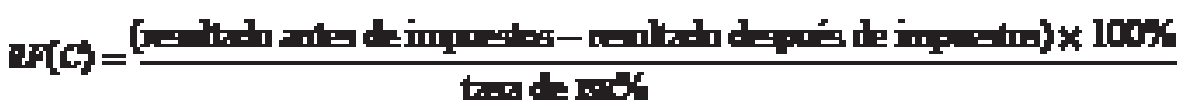

La ecuación (2) se propone considerando que algunas empresas reportan en sus estados financieros la partida de ISR diferido con saldos positivos. La ecuación (3) se utiliza porque la principal diferencia entre el resultado antes de impuestos y el resultado después de impuestos es precisamente la contribución fiscal al ingreso.

La utilidad o pérdida fiscal se estimó a partir de:

$$
\begin{aligned}
& U F(\lambda)=F(\Delta)+F T \\
& U P(\mathbb{B})=F(D)+P T H \\
& U F(c)=n T(c)+F T \\
& U P(A)=I F(A)+P H U-E R
\end{aligned}
$$


donde PTU es la participación de los trabajadores en las utilidades de las empresas; las ecuaciones (4) a (6) suponen que la principal diferencia entre el resultado fiscal y la utilidad o pérdida fiscal está dado por PTU. Se consideró oportuno incluir la ecuación (7) porque con ésta se reduce la utilidad fiscal, y se sigue un procedimiento más cercano al del cuadro A.3 (anexo A). Las deducciones autorizadas se estimaron así: ${ }^{16}$

$$
\begin{aligned}
& \text { DA(A) = uilitad n:ta }-W(A) \\
& \text { DA(x) = wilitad n:ta }-W(s) \\
& \text { DA(c) = ufilithed ath }-W(C)
\end{aligned}
$$

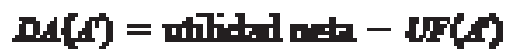

En el cuadro A.4 (anexo A) se presenta un ejemplo de la estimación del resultado fiscal, la utilidad fiscal y las deducciones autorizadas para una de las empresas. Por simplicidad, sólo se muestra un esquema para el ejercicio fiscal de 2010, pero los cálculos se efectuaron desde la fecha de registro de la empresa en la BMV hasta el primer trimestre de 2011.

En el cuadro 6 se muestran los resultados generales de las estimaciones de las ecuaciones (1) a (11), que se obtuvieron a partir de cifras desacumuladas y constantes; estos resultados indican la proporción de las deducciones autorizadas respecto de la utilidad neta de las empresas; por ejemplo, para las empresas cuyas series accionarias son parte del IPC LargeCap, la estimación mediante la ecuación (8) de las deducciones autorizadas sugiere que éstas representan 25\% de las utilidades netas entre los años 1993 y 2011, pero si las deducciones autorizadas se estiman a partir de la ecuación (10), entonces representan $60 \%$ de las utilidades netas. A partir de los resultados del cuadro 6, también se aprecia menor variabilidad de las razones que representan las deducciones autorizadas en el caso de los grupos: IPC MidiCap, Telecom RT y Comercio RT. Los signos negativos que resultan en algunos casos no significan que las deducciones autorizadas

\footnotetext{
${ }^{16}$ En las ecuaciones (8) a (11) las deducciones autorizadas se estimaron a partir de la utilidad neta, para seguir la relación establecida en el procedimiento de conciliación contable y fiscal. Véase cuadro A3 (anexo A).
} 
hayan sido negativas; los resultados negativos en las ecuaciones (8) a (11) son consecuencia del procedimiento fiscal y contable. ${ }^{17}$

Cuadro 6. Resultados estimados para la proporción de deducciones autorizadas respecto a la utilidad neta en las empresas registradas en la Bolsa Mexicana de Valores (resultados promedio para el periodo 1993-2011)

\begin{tabular}{|l|r|r|r|c|}
\hline \multicolumn{1}{|c|}{ Grupo de empresas } & $D A(A) / U N$ & $D A(B) / U N$ & $D A(C) / U N$ & $D A\left(A^{\prime}\right) / U N$ \\
\hline 1. IPC & $53 \%$ & $186 \%$ & $-74 \%$ & $70 \%$ \\
2. INMEX & $-13 \%$ & $-48 \%$ & $49 \%$ & $22 \%$ \\
3. IPC LargeCap & $25 \%$ & $12 \%$ & $60 \%$ & $47 \%$ \\
4. IPC MidiCap & $10 \%$ & $10 \%$ & $10 \%$ & $38 \%$ \\
5. IPC SmallCap & $2 \%$ & $-6 \%$ & $12 \%$ & $32 \%$ \\
6. Telecom RT & $31 \%$ & $28 \%$ & $17 \%$ & $54 \%$ \\
7. Construye RT & $170 \%$ & $340 \%$ & $-4 \%$ & $148 \%$ \\
8. Comercio RT & $5 \%$ & $2 \%$ & $8 \%$ & $34 \%$ \\
9. Sector industrial & $-239 \%$ & $-360 \%$ & $-150 \%$ & $-131 \%$ \\
10. Sector de servicios y bienes de \\
consumo no básico
\end{tabular}

Nota: Los datos negativos se explican por el procedimiento de conciliación fiscal y contable. $D A=$ deducciones autorizadas, $U N=$ utilidad neta.

Fuente: Elaboración propia.

\footnotetext{
${ }^{17}$ Por ejemplo, supongamos que una empresa paga por ISR $\$ 90000.00$ y la tasa impositiva es de $30 \%$, lo que genera un resultado fiscal de $\$ 300000$ (ecuación (1)). Ahora bien, el resultado de las deducciones autorizadas depende de la relación entre la utilidad neta, la utilidad fiscal, la participación de los trabajadores en las utilidades y el impuesto sobre la renta. Podríamos tener los siguientes casos: a) Asumiendo que los datos conocidos en los estados financieros son $P T U=$ $\$ 105000$ y $U N=\$ 160000$, esto significa una utilidad fiscal de $\$ 405000$ (ecuación (4)) y deducciones por -\$245 000 (ecuación (8)). b) Mediante un procedimiento similar, pero incluyendo el ISR en el cálculo de la utilidad fiscal se tendría que $U F=\$ 104000$ (ecuación (7)) y en consecuencia un monto de deducciones autorizadas de $\$ 56000$ (ecuación (11)).

Las deducciones negativas obtenidas en el inciso a) son sólo un resultado algebraico del procedimiento de conciliación fiscal y contable, pero en realidad puede comprobarse que son positivas siguiendo el método del cuadro A.3 (anexo A), es decir, mediante la fórmula para obtener la utilidad fiscal antes de $P T U: U N+U N+I F N C+D C N F+D F N C+I C N F=R F$. En los estados financieros no pueden identificarse los términos $I F N C, D C N F, D F N C$ e $I C N F$, pero, $R F-U N=\$ 300000-$ $\$ 160000=\$ 140000$, es decir, el monto de deducciones autorizadas sin incluir PTU.
} 


\section{Tasas efectivas de impuesto y estimaciones de la recaudación potencial de ISR}

Con el fin de determinar cuantitativamente el grado de gasto fiscal por ISR en personas morales, se proponen los siguientes indicadores (algunos se han utilizado en investigaciones sobre la situación fiscal en Estados Unidos, pero no se conocen estudios con aplicaciones similares para México):

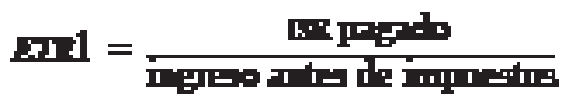

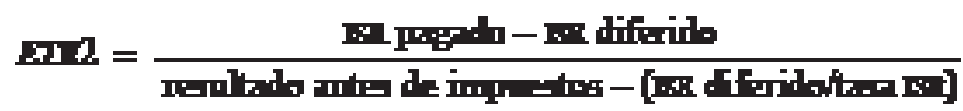

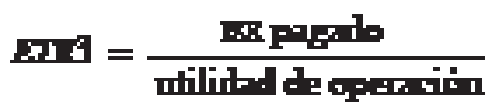

En (12) se mide la tasa efectiva de impuesto (ETR) pagado como la razón del ISR pagado y el ingreso antes de impuestos. Se trata de un indicador que ha sido utilizado en Estados Unidos para analizar la contribución que verdaderamente proviene de las empresas (Hanlon y Heitzman, 2010, pp. 13 y ss.). La ecuación (13) fue propuesta por Stickney y McGee (1982), y se discute su aplicación en Plesko (2003). La ecuación (14) establece la razón entre el ISR pagado y la utilidad de operación (antes de intereses e impuestos); es usada en Gupta y Newberry (1997). La interpretación de las razones es la siguiente: entre mayor sea ET1, ET2 y ET3 se evidencia un mayor pago de impuestos o menor gasto fiscal. Las ecuaciones (12) a (14) fueron aplicadas a cada una de las empresas registradas en la BMV en el periodo 1993-2011; un ejemplo de los cálculos se muestra en el cuadro A6 (anexo A).

Los resultados generales de (12) a (14) se muestran en el cuadro 7, y representan la tasa efectiva de impuesto pagada por las empresas. La ecuación (13) proporciona alta variabilidad en sus resultados, es decir, ETR2, para los diferentes grupos de empresas, pero son más homogéneas las otras medidas. Considerando, como ejemplo, los valores de ETR1, éstos indicarían que en promedio las empresas cuyas acciones son parte del IPC pagan una tasa efectiva de impuesto de $8.58 \%$; las empresas con acciones en el índice Telecom RT, $13.04 \%$, y las del IPC MidiCap, 13.48\%; en comparación, la tasa normativa ha sido en promedio de 
$30 \%$. Es importante también resaltar que las empresas del grupo Comercio RT y del grupo del sector de servicios y bienes de consumo no básico son las que reportan mayores valores de tasa efectiva de impuesto pagada; esta situación se aprecia sistemáticamente en las estimaciones individuales y en las del grupo en su conjunto. En el caso de Comercio RT, estos resultados pueden explicarse por las menores deducciones autorizadas. Los resultados negativos (de ETR2) se explican porque en promedio, para el grupo de empresas el ISR pagado es menor que el diferido.

Cuadro 7. Resultados estimados de la tasa efectiva de impuesto (ETR) pagada en las empresas registradas en la Bolsa Mexicana de Valores (resultados promedio para el periodo 1993-2011)

\begin{tabular}{|l|c|c|c|}
\hline \multicolumn{1}{|c|}{ Grupo de empresas } & ETR1 & ETR2 & ETR3 \\
\hline 1. IPC & $8.58 \%$ & $13.24 \%$ & $18.28 \%$ \\
2. INMEX & $14.14 \%$ & $-13.83 \%$ & $16.15 \%$ \\
3. PC LargeCap & $23.62 \%$ & $21.89 \%$ & $24.07 \%$ \\
4. IPC MidiCap & $13.48 \%$ & $-2.93 \%$ & $16.46 \%$ \\
5. IPC SmallCap & $16.93 \%$ & $7.26 \%$ & $16.59 \%$ \\
6. Telecom RT & $13.04 \%$ & $20.81 \%$ & $14.10 \%$ \\
7. Construye RT & $26.19 \%$ & $-34.45 \%$ & $18.16 \%$ \\
8. Comercio RT & $29.68 \%$ & $28.12 \%$ & $24.49 \%$ \\
9. Sector industrial & $15.94 \%$ & $-0.72 \%$ & $13.62 \%$ \\
10. Sector de servicios y bienes de consumo \\
no básico & $19.84 \%$ & $35.88 \%$ & $30.00 \%$ \\
\hline
\end{tabular}

Fuente: Elaboración propia.

La principal base de comparación de estos resultados son algunas investigaciones realizadas para los Estados Unidos, debido a que no se conocen estudios similares para México. Por ejemplo, en Gupta y Newberry (1997), las empresas se clasifican en extractivas, manufactura de bienes no durables, manufactura de bienes durables, comercio, servicios varios y servicios profesionales; y a partir del cálculo de la tasa efectiva de impuesto, los autores encuentran que casi todas las empresas pagan una tasa sobre sus ingresos de entre $20 \%$ y $29 \%$, con excepción de las que pertenecen al sector extractivo, para las que el monto 
oscila entre $11 \%$ y $17 \%$. Otra referencia útil con fines comparativos es el trabajo de Dyreng, Hanlon y Maydew (2008), donde a partir de una clasificación de las empresas en 25 categorías, se encuentra que las que pertenecen al sector de las telecomunicaciones pagan una tasa efectiva de impuestos de sólo 7.3\%; las del sector aéreo, $8.1 \%$; las del sector de entretenimiento, $10.3 \%$; las automotrices, $13.2 \%$, y las farmacéuticas, $14.3 \%$.

Como se mencionó en la sección II.1, Antón (2005) realiza estimaciones de las tasas efectivas pagadas por impuestos con base en estadísticas de ingresos de la OCDE y del Sistema de Cuentas Nacionales de México; el autor encuentra que para el periodo 1988-2002, la tasa efectiva del impuesto al trabajo fluctúa entre $8 \%$ y $12.5 \%$, y el impuesto al capital entre $8 \%$ y $15 \%$. Aunque los resultados que se muestran en el cuadro 7 presentan mayor variabilidad, sí son más convergentes con los de Antón en el caso de las empresas que pertenecen al IPC, INMEX, IPC MidiCap, IPC SmallCap y al sector industrial; en otros casos, como los de las empresas del IPC LargeCap o de Comercio RT, la tasa efectiva de impuesto es mayor a 20\%. También conviene señalar que en Antón (2005) sólo se utiliza información a nivel agregado, mientras que con la metodología que aquí se sigue, es posible estimar las tasas efectivas de impuestos para los distintos grupos de empresas que cotizan en la bolsa.

Finalmente, en el documento se estiman tres medidas de recaudación potencial, utilizando las siguientes ecuaciones:

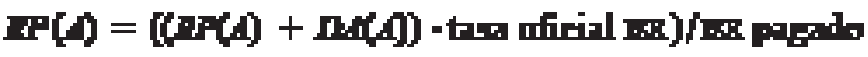

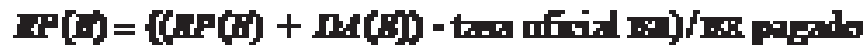

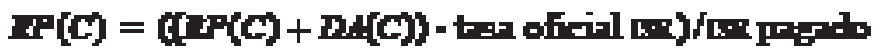

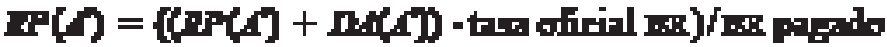

En el cuadro 8 se presentan tres escenarios alternativos de recaudación potencial por el pago de ISR de personas morales; se trata del número de veces la recaudación efectiva observada del ISR que se lograría si se prescindiera de las deducciones autorizadas; por ejemplo, para $R P(B)$, si se omitieran los beneficios fiscales de las firmas incluidas en el INMEX se obtendría 2.44 veces la 
recaudación actual, mientras que con las empresas del índice Construye RT se obtendría 1.59 veces la recaudación actual. Cada uno de los cuatro escenarios, $R P(A), R P(B), R P(C)$ y $R P\left(A^{\prime}\right)$, se elaboró a partir de las diferentes estimaciones de deducciones autorizadas consideradas en las ecuaciones (8) a (11).

Cuadro 8. Resultados estimados de la recaudación potencial (RP) entre las empresas registradas en la Bolsa Mexicana de Valores (resultados promedio para el periodo 1993-2011)

\begin{tabular}{|l|l|l|l|l|}
\hline \multicolumn{1}{|c|}{ Grupo de empresas } & $R P(A)$ & $R P(B)$ & $R P(C)$ & $R P\left(A^{\prime}\right)$ \\
\hline 1. IPC & 1.5562 & 1.7024 & 1.7024 & 1.8762 \\
2. INMEX & 2.5606 & 2.4453 & 2.4453 & 2.8806 \\
3. PC LargeCap & 1.5897 & 1.5614 & 1.5614 & 1.9168 \\
4. IPC MidiCap & 1.5053 & 1.5707 & 1.5707 & 1.8041 \\
5. IPC SmallCap & 3.8094 & 4.9193 & 4.9193 & 4.2500 \\
6. Telecom RT & 1.7775 & 2.1017 & 2.1017 & 2.0946 \\
7. Construye RT & 0.3398 & 1.5908 & 1.5908 & 0.6458 \\
8. Comercio RT & 1.0843 & 0.8437 & 0.8437 & 1.4014 \\
9. Sector industrial & 1.6328 & 2.0293 & 2.0293 & 1.9449 \\
10. Sector de servicios y bienes de consumo \\
no básico & 0.8826 & 0.5414 & 0.5414 & 1.2052 \\
\hline
\end{tabular}

Nota: Las cifras indican el número de veces que aumentaría la recaudación por ISR de las personas morales, respecto a la observada, si se prescindiera de las deducciones autorizadas.

Fuente: Elaboración propia.

A partir de los resultados del cuadro 8, también es posible calcular una tasa de pérdida en la recaudación por ISR mediante:

$$
\boldsymbol{I P}_{\mathbf{n}}=1-\frac{1}{\operatorname{sP(x)}}
$$

donde $T P R_{I S R}$ es la tasa de pérdida en la recaudación por ISR, $R P(x)$ es la recaudación potencial calculada de acuerdo con las ecuaciones (15) a (18). Si se realiza este cálculo para las empresas del IPC (primera fila del cuadro 8), se obtienen tasas de $35.74 \%, 41.25 \%, 41.25 \%$ y $46.70 \%$. Aunque las tasas de pérdida calculadas no son exactamente de evasión (porque se construyen a partir de la estima- 
ción de las deducciones autorizadas, es decir, del monto total por las partidas que legalmente permiten disminuir la base gravable), es interesante compararlas con los resultados de Bergman, Carreón y Hernández (2005), quienes encuentran que las tasas de evasión de ISR para personas morales, en los años 2002 y 2003, representan $32.6 \%$ y $39.5 \%$ de la recaudación potencial y con los resultados de Samaniego, Endo, Mendoza y Zorrilla (2006), quienes reportan que las tasas de evasión (también de personas morales) oscilaron de 26\% a 37\% entre los años 1998 y 2004. Conviene precisar que ambos trabajos basan su análisis en datos agregados de la economía mexicana (Sistema de Cuentas Nacionales) y especialmente en las variables excedente neto de explotación (Bergman, Carreón y Hernández, 2005, p. 40) y excedente neto de operación (Samaniego, Endo, Mendoza y Zorrilla, 2006, p. 111), en cambio, los resultados del cuadro 8 permiten estimar las tasas de pérdida en la recaudación para los distintos grupos de empresas que cotizan en la bolsa.

\section{CONCLUSIONES}

Diversos sectores de la sociedad mexicana coinciden en que la recaudación tributaria en nuestro país es inferior al potencial recaudatorio, y en torno a este hecho se han generado diversos espacios de discusión en los que se argumenta sobre la necesidad de ampliar la base de contribuyentes, revisar las cargas fiscales de los contribuyentes cautivos, la progresividad de las tasas impositivas, evaluar la eficiencia de los incentivos fiscales, reducir las exenciones y deducciones fiscales, mejorar la eficiencia recaudatoria, la introducción de nuevos impuestos, etcétera.

La presente investigación, centrada en la recaudación tributaria por ISR proveniente de las personas morales, esto es, el sector que aporta la parte proporcionalmente mayor del impuesto más importante en términos de ingresos tributarios, muestra que es posible incrementar la recaudación mediante un ejercicio que recupera los principios constitucionales de proporcionalidad y equidad. En todo caso, la sugerencia es establecer mecanismos que permitan incrementar la tasa efectivamente pagada de ISR por las personas morales, haciendo una revisión profunda del gasto fiscal y controlando la evasión.

Por otra parte, este trabajo hace patente que el esfuerzo que realiza el Estado mexicano en términos de gasto fiscal no se traduce en una elevación significativa de la recaudación tributaria. Oficialmente, el gasto fiscal llega a representar 3\% del PIB. Rubros importantes del presupuesto federal para el desarrollo 
social del país, por ejemplo, en ciencia y tecnología, no alcanzan a recibir un monto similar de recursos.

En la investigación se realizaron las siguientes aportaciones: el análisis de la recaudación del ISR comparando el pago tributario por tipo de contribuyente; la evaluación de la contribución efectiva al ISR de las personas morales bajo el régimen general a partir de la comparación entre las utilidades netas y el impuesto pagado, utilizando como base los estados financieros de las empresas con mayor capitalización en México registradas en la Bolsa Mexicana de Valores; la cuantificación de las diferentes fuentes (exenciones y deducciones fiscales) que propician la disminución de la recaudación entre las personas morales, y la construcción de escenarios que muestran la recaudación potencial de ISR en personas morales del régimen general.

Cuantitativamente, a partir del análisis de los estados financieros de las empresas registradas en la Bolsa Mexicana de Valores, fue posible determinar los siguientes resultados: 1) Existe una amplia brecha entre las utilidades netas y el pago efectivo de ISR, que incluso no siguen una tendencia similar: mientras que éste se incrementa paulatinamente, aquéllas aumentan en mayor grado (con excepción de las compañías del IPC SmallCap y las del sector de servicios y bienes de consumo no básico). 2) Se construyeron indicadores alternativos que estiman el resultado fiscal, la utilidad o pérdida fiscal y las deducciones autorizadas; estos indicadores se calcularon para cada empresa y los resultados globales se resumieron estimando la proporción que representan las deducciones autorizadas respecto a la utilidad neta. 3) Se construyeron razones de gasto fiscal que miden la tasa efectiva de impuesto pagada (utilizando, por ejemplo, la razón ETR 1 se encontró que, en el mejor de los casos, los contribuyentes del índice Comercio RT aportan una tasa de $29.68 \%$, pero, en el otro extremo, los del IPC aportan $8.58 \%$, ambos respecto a una tasa promedio del ISR de 30\%). 4) A partir de las estimaciones de las deducciones autorizadas se construyeron escenarios alternativos de recaudación potencial por ISR, que indican el número de veces que se obtendría el monto actual si se prescindiera de las deducciones autorizadas (por ejemplo, entre las empresas del INMEX se obtendría 2.5 veces la recaudación presente).

Es importante resaltar que la metodología utilizada para el análisis de las aportaciones efectivas al ISR por parte de las personas morales constituye una aportación relevante que permite avanzar en la comprensión de las causas del rezago en materia tributaria. Además, se han reseñado varios estudios sistemáticos que dan cuenta de la conducta de las empresas de Estados Unidos en relación 
con el pago de impuestos sobre sus ingresos, sin embargo, no se conocen trabajos que sigan una metodología similar para el caso de México.

Por supuesto, el trabajo no está exento de algunas omisiones y posibilidades de mejora que están pendientes en la agenda de investigación futura. Se señalaron ya, en la sección II, algunos ejemplos de estudios que pueden servir como base a las necesidades de investigación para el caso mexicano. Algunas cuestiones metodológicas de la presente investigación que podrían revisarse son: evaluar si la clasificación empleada como base es adecuada o si podrían ensayarse otras clasificaciones que refuercen los resultados, realizar un estudio técnico detallado de la pertinencia de los indicadores construidos y extender los resultados para observar la correlación entre incremento del PIB por sector de actividad económica, inversión y generación de empleos, con los beneficios fiscales otorgados a las empresas.

Es de señalar que la investigación sugiere como acciones inmediatas de las autoridades legislativa y hacendaria revisar la pertinencia de los beneficios fiscales otorgadas a las personas morales, principalmente mediante su asociación con las variables macroeconómicas que interesa mejorar, así como generar medidas que mejoren la determinación presuntiva del ISR de las personas morales y que, con ello, incrementen la eficiencia recaudatoria. México es un país cuya vida social y productiva se asienta en una estructura de graves desigualdades, y con grandes rezagos sociales en amplios sectores de la población. Elevar la eficiencia recaudatoria, con base en los principios de proporcionalidad y equidad en el tratamiento de los sujetos pasivos, constituye una tarea fundamental y un elemento central en la discusión de la reforma fiscal en la agenda nacional. 
38 ECONOMÍA: TEORÍA Y PRÁCTICA • Nueva Época, número 38, enero-junio 2013

ANEXOA

Cuadro A1. Esquema del estado de resultados (resultado contable)

\begin{tabular}{|c|c|c|}
\hline & Concepto & Cantidades \\
\hline & Ventas nacionales & \\
\hline$(-)$ & Devoluciones sobre ventas & \\
\hline \multirow[t]{2}{*}{$(=)$} & Ventas netas & \\
\hline & Inventario inicial & \\
\hline$(+)$ & Compras netas & \\
\hline$(-)$ & Inventario final & \\
\hline \multirow[t]{2}{*}{$(=)$} & Costo de las mercancías & \\
\hline & Utilidad bruta (ventas netas - costo de las mercancías) & \\
\hline$(-)$ & Gastos de operación & \\
\hline \multirow[t]{3}{*}{$(=)$} & Utilidad de operación & \\
\hline & Intereses devengados a favor & \\
\hline & Intereses devengados a cargo & \\
\hline \multirow[t]{3}{*}{$(=)$} & Resultado integral de financiamiento & \\
\hline & Ingresos por partidas discontinuas & \\
\hline & Gastos por partidas discontinuas & \\
\hline$(=)$ & Utilidad de operación & \\
\hline$(+)$ & Resultado integral de financiamiento & \\
\hline$(+)$ & Ingresos por partidas discontinuas & \\
\hline$(-)$ & Gastos por partidas discontinuas & \\
\hline$(\Rightarrow)$ & Utilidad antes de impuestos & \\
\hline$(-)$ & ISR & \\
\hline$(-)$ & IETU & \\
\hline$(-)$ & PTU & \\
\hline$(=)$ & Utilidad neta & \\
\hline
\end{tabular}

Fuente: Adaptado de SAT (2010, p. 19). 


\section{Cuadro A2. Esquema del resultado fiscal para el cálculo del ISR en personas morales}

\begin{tabular}{|c|l|l|}
\hline & \multicolumn{1}{|c|}{ Concepto } & Cantidades \\
\hline & Total de ingresos acumulables & \\
\hline$(-)$ & Total de deducciones autorizadas & \\
\hline$(=)$ & Utilidad fiscal o pérdida fiscal del ejercicio & \\
\hline$(-)$ & PTU pagada en el ejercicio & \\
\hline$(-)$ & Estímulo fiscal por deducción inmediata de inversiones & \\
\hline$(-)$ & Pérdidas fiscales de ejercicios anteriores que se aplican en el ejercicio & \\
\hline$(=)$ & Resultado fiscal & \\
\hline$(x)$ & Tasa del ISR & \\
\hline$(=)$ & ISR causado en el ejercicio & \\
\hline$(-)$ & Estímulos por proyectos en investigación y desarrollo tecnológico & \\
\hline$(-)$ & Pagos provisionales del ISR efectuados en el ejercicio & \\
\hline$(-)$ & ISR retenido al contribuyente durante el ejercicio & \\
\hline$(-)$ & ISR acreditable por dividendos o por utilidades distribuidas & \\
\hline$(-)$ & ISR acreditable pagado en el extranjero & \\
\hline$(=)$ & ISR a cargo & \\
\hline$(-)$ & Impuesto acreditable por depósitos en efectivo del ejercicio & \\
\hline$(=)$ & ISR a cargo del ejercicio & \\
\hline
\end{tabular}

Fuente: Adaptado de SAT (2010, p. 28).

Cuadro A3. Conciliación contable y fiscal (continúa)

\begin{tabular}{|c|l|c|}
\hline \multicolumn{1}{|c|}{ Concepto } & Saldo \\
\hline & Utilidad o pérdida neta (UN) & \\
\hline$(-)$ & Efectos de reexpresión & \\
\hline$(-)$ & Resultado por posición monetaria & \\
\hline$(=)$ & Utilidad o pérdida neta histórica & \\
\hline$(+)$ & Ingresos fiscales no contables (IFNC) & \\
\hline & Ajuste anual por inflación acumulable & \\
\hline & Anticipos de clientes & \\
\hline & Intereses moratorios efectivamente cobrados & \\
\hline & Ganancia en la enajenación de acciones o por reembolso de capital & \\
\hline & Ganancia en la enajenación de terrenos y activo fijo & \\
\hline & Inventario acumulable del ejercicio & \\
\hline & Otros ingresos fiscales no contables & \\
\hline
\end{tabular}


40 ECONOMÍA: TEORÍA Y PRÁCTICA • Nueva Época, número 38, enero-junio 2013

\section{Cuadro A3. Conciliación contable y fiscal (concluye)}

\begin{tabular}{|c|c|c|}
\hline & Concepto & Saldo \\
\hline \multirow[t]{10}{*}{$(+)$} & Deducciones contables no fiscales (DCNF) & \\
\hline & Costo de ventas contable & \\
\hline & Depreciación y amortización contable & \\
\hline & Gastos que no reúnen requisitos fiscales & \\
\hline & ISR, IETU, IMPAC Y PTU & \\
\hline & Pérdida contable en enajenación de acciones & \\
\hline & Pérdida contable en enajenación de activo fijo & \\
\hline & Pérdida en participación subsidiaria & \\
\hline & Intereses devengados que exceden del valor de mercado y moratorios pagados o no & \\
\hline & Otras deducciones contables no fiscales & \\
\hline \multirow[t]{14}{*}{$(-)$} & Deducciones fiscales no contables (DFNC) & \\
\hline & Ajuste anual por inflación deducible & \\
\hline & Adquisiciones netas de mercancías, materias primas, productos semiterminados o terminados & \\
\hline & Costo de lo vendido fiscal & \\
\hline & Mano de obra directa & \\
\hline & Maquilas & \\
\hline & Gastos indirectos de fabricación & \\
\hline & Deducción de inversiones & \\
\hline & Estímulo fiscal por deducción inmediata de inversiones & \\
\hline & Estímulo fiscal de las personas con discapacidad y/o adultos mayores & \\
\hline & Pérdida fiscal en enajenación de acciones & \\
\hline & Pérdida fiscal en enajenación de terrenos y activo fijo & \\
\hline & Intereses moratorios efectivamente pagados & \\
\hline & Otras deducciones fiscales no contables & \\
\hline \multirow[t]{7}{*}{$(-)$} & Ingresos contables no fiscales (ICNF) & \\
\hline & Intereses moratorios devengados a favor cobrados o no & \\
\hline & Anticipos de clientes de ejercicios anteriores & \\
\hline & Saldos a favor de impuestos y su actualización & \\
\hline & Utilidad contable en enajenación de acciones & \\
\hline & Utilidad en participación subsidiaria & \\
\hline & Otros ingresos contables no fiscales & \\
\hline$(=)$ & Utilidad o pérdida fiscal antes de PTU & \\
\hline
\end{tabular}

Fuente: Adaptado de SAT (2010, p. 25). 
Cuadro A4. Ejemplo de las estimaciones de resultado fiscal, utilidad o pérdida fiscal y deducciones autorizadas para la empresa $\mathrm{x}$ registrada en la Bolsa Mexicana de Valores

\begin{tabular}{|c|c|c|c|c|}
\hline & $31 / 03 / 2010$ & $30 / 06 / 2010$ & $30 / 09 / 2010$ & $31 / 12 / 2010$ \\
\hline Tasa & $29 \%$ & $30 \%$ & $30 \%$ & $30 \%$ \\
\hline Resultado fiscal $(A)$ & 1134858.62 & 590676.67 & 572243.33 & 3084770.00 \\
\hline Resultado fiscal (B) & 736455.17 & -604283.33 & -178196.67 & 5071100.00 \\
\hline Resultado fiscal (C) & -4894103.45 & -2894133.33 & -3268936.67 & -8001090.00 \\
\hline Utilidad o pérdida fiscal estimada $(A)$ & 1168429.62 & 634101.67 & 608689.33 & 3155336.00 \\
\hline Utilidad o pérdida fiscal estimada $(B)$ & 770026.17 & -560858.33 & -141750.67 & 5141666.00 \\
\hline Utilidad o pérdida fiscal estimada (C) & -4860532.45 & -2850708.33 & -3232490.67 & -7930524.00 \\
\hline Utilidad o pérdida fiscal estimada $\left(A^{\prime}\right)$ & 839320.62 & 456898.67 & 437016.33 & 2229905.00 \\
\hline Deducciones autorizadas estimadas $(A)$ & -46209.62 & 132005.33 & 165366.67 & -891034.00 \\
\hline Deducciones autorizadas estimadas $(B)$ & 352193.83 & 1326965.33 & 915806.67 & -2877364.00 \\
\hline Deducciones autorizadas estimadas (C) & 5982752.45 & 3616815.33 & 4006546.67 & 10194826.00 \\
\hline Deducciones autorizadas estimadas $\left(A^{\prime}\right)$ & 282899.38 & 309208.33 & 337039.67 & 34397.00 \\
\hline
\end{tabular}

Nota: Estimaciones y unidades en miles de pesos mexicanos.

Fuente: Elaboración propia.

Cuadro A5. Ejemplo de las medidas de gasto fiscal y medidas de recaudación fiscal estimadas para la empresa x registrada en la Bolsa Mexicana de Valores

\begin{tabular}{|l|c|c|c|c|}
\hline & $31 / 03 / 2010$ & $30 / 06 / 2010$ & $30 / 09 / 2010$ & $31 / 12 / 2010$ \\
\hline Medidas de gasto fiscal (porcentaje) & & & & \\
ETR1 & 0.1766 & 0.1262 & 0.1246 & 0.3390 \\
ETR2 & 0.2929 & -0.2229 & -0.0664 & -4.2865 \\
ETR3 & 0.2319 & 0.2041 & 0.1751 & 0.3855 \\
Medidas de recaudación potencial & & & & \\
(número de veces la recaudación actual) & & & & \\
Recaudación potencial $(A)$ & 1.0407 & 1.2235 & 1.2890 & 1.2888 \\
Recaudación potencial $(B)$ & 0.9593 & 1.2235 & 1.2890 & 2.5767 \\
Recaudación potencial (C) & 0.9593 & 1.2235 & 1.2890 & 0.7112 \\
Recaudación potencial $\left(A^{\prime}\right)$ & 1.2493 & 1.5235 & 1.5890 & 1.0112 \\
\hline
\end{tabular}

Fuente: Elaboración propia. 


\section{ANEXo B}

Las empresas registradas en la Bolsa Mexicana de Valores que integran cada grupo de la muestra utilizada son las siguientes, de acuerdo con el índice bursátil en el que se cotizan (se excluyen los grupos financieros):

1. Índice de Precios y Cotizaciones (IPC). Es el de mayor representatividad del mercado mexicano de valores; se constituye por las series accionarias cuyo valor de capitalización es igual o mayor a $0.1 \%$ de la capitalización total del IPC.

Emisoras y empresas (34): AC (ARCA Continental, S. A. B. de C. V.), ALFA (Alfa, S. A. B. de C. V.), Amx (América Móvil, S. A. B. de C. V.), ARA (Consorcio Ara, S. A. B. de C. V.), AZUR (Grupo Aeroportuario del Sureste, S. A. B. de C. V.), AXtel (Axtel, S. A. B. de C. V.), azteca (TV Azteca, S. A. B. de C. V.), BImBo (Grupo Bimbo, S. A. B. de C. V.), CEMEX (Cemex, S. A. B. de C. V.), CHEDRAUI (Grupo Comercial Chedraui, S. A. B. de C. V.), COMERCI (Controladora Comercial Mexicana, S. A. B. de C. V.), ELEKTRA (Grupo Elektra, S. A. de C. V.), FEMSA (Fomento Económico Mexicano, S. A. B. de C. V.), GaP (Grupo Aeroportuario del Pacífico, S. A. B. de C. V.), GCARSO (Grupo Carso, S. A. B. de C. V.), GEO (Corporación GEO, S. A. B. de C. V.), GISSA (Grupo Industrial Saltillo, S. A. B. de C. V.), GMEXICO (Grupo México, S. A. B. de C. V.), GMOdelo (Grupo Modelo, S. A. B. de C. V.), GRUMA (GRUMA, S. A. B. de C. V.), HOMEX (Desarrolladora Homex, S. A. B. de C. V.), Desarrolladora ICA (Empresas ICA, S. A. B. de C. V.), ICH (Industrias CH, S. A. B. de C. V.), InCARso (Inmuebles Carso, S. A. B. de C. V.), KimBer (KimberlyClark de México, S. A. B. de C. V.), LAB (Genomma Lab Internacional, S. A. B. de C. V.), MEXChEM (Mexichem, S. A. B. de C. V.), MFRISCO (Minera Frisco, S. A. B. de C. V.), PEÑOles (Industrias Peñoles, S. A. B. de C. V.), SORIANA (Organización Soriana, S. A. B. de C. V.), TelmeX (Teléfonos de México, S. A. B. de C. V.), TELEVISA (Grupo Televisa, S. A. ), URBI (Urbi Desarrollos Urbanos, S. A. B. de C. V.), WalmeX (Wal Mart de México, S. A. B. de C. V.).

2. Índice México de Rendimiento Total (INMEX). Es altamente representativo del mercado accionario mexicano y se constituye por las series accionarias cuyo valor de capitalización es igual o mayor a $0.1 \%$ de la capitalización total del INMEX; fue creado para establecerse como valor subyacente en emisiones de productos derivados. 
Emisoras y empresas (18): ALFA (ALFA, S. A. B. de C. V.), AMX (América Móvil, S. A. B. de C. V.), AXtel (Axtel, S. A. B. de C. V.), CemeX (Cemex, S. A. B. de C. V.), GAP (Grupo Aeroportuario del Pacífico, S. A. B. de C. V.), GEO (Corporación GEO, S. A. B. de C. V.), GMeXICo (Grupo México, S. A. B. de C. V.), GMODElo (Grupo Modelo, S. A. B. de C. V.), HOMEX (Desarrolladora Homex, S. A. B. de C. V.), ICA (Empresas ICA, S. A. B. de C. V.), KIMBER (Kimberly-Clark de México, S. A. B. de C. V.), MeXChem (Mexichem, S. A. B. de C. V.), PeÑoles (Industrias Peñoles, S. A. B. de C. V.), SORIANA (Organización Soriana, S. A. B. de C. V.), TelmeX (Teléfonos de México, S. A. B. de C. V.), TELEVISA (Grupo Televisa, S. A.), URBI (Urbi Desarrollos Urbanos, S. A. B. de C. V.), WalmeX (Wal Mart de México, S. A. B. de C. V.).

3. IPC LargeCap. Incluye a las empresas de mayor capitalización dentro de la muestra del Índice Compuesto.

Emisoras y empresas (18): ALFA (ALFA, S. A. B. de C. V.), AMX (América Móvil, S. A. B. de C. V.), Bimbo (Grupo Bimbo, S. A. B. de C. V.), CEMEX (Cemex, S. A. B. de C. V.), ElekTra (Grupo Elektra, S. A. de C. V.), FEMSA (Fomento Económico Mexicano, S. A. B. de C. V.), GCARSo (Grupo Carso, S. A. B. de C. V), GMeXico (Grupo México, S. A. B. de C. V.), GMOdelo (Grupo Modelo, S. A. B. de C. V.), InCARso (Inmuebles Carso, S. A. B. de C. V.), KimBer (Kimberly-Clark de México, S. A. B. de C. V.), KOF (CocaCola Femsa, S. A. B. de C. V.), MEXchem (Mexichem, S. A. B. de C. V.), MFrisco O (Minera Frisco, S. A. B. de C. V.), PEÑoles (Industrias Peñoles, S. A. B. de C. V.), SORIANA (Organización Soriana, S. A. B. de C. V.), TELmeX (Teléfonos de México, S. A. B. de C. V.), TELEVISA (Grupo Televisa, S. A.), WAlmeX (Wal Mart de México, S. A. B. de C. V.).

4. IPC MidiCap, Incluye a las empresas de capitalización media dentro de la muestra del Índice Compuesto.

Emisoras y empresas (18): ASUR (Grupo Aeroportuario del Sureste, S. A. B. de C. V.), aXtel (Axtel, S. A. B. de C. V.), azteca (tv Azteca, S. A. B. de C. V.), CHDRAUI (Grupo Comercial Chedraui , S. A. B. de C. V.), CICSA (Carso Infraestructura y Construcción, S. A. B. de C. V.), GAP (Grupo Aeroportuario del Pacífico, S. A. B. de C. V.), GEO (Corporación GEO, S. A. B. de C. V.), HomeX (Desarrolladora Homex, S. A. B. de C. V.), ICA (Empresas ICA, S. A. B. de C. V.), ICH (Industrias CH, S. A. B. de C. V.), IDEAL (Impulsora del Desarrollo y el Empleo en América Latina, S. A. B. de C. V.), LIVEPOL (El Puerto de Liverpool, S. A. B. de C. V.), MEGA (Mega cable Holdings, S. A. B. de C. V.), OHLMeX (OHL México, S. A. B. de C. V.), PINFRA (Promotora 
y Operadora de Infraestructura, S. A. B. de C. V.), MEXCHEM (Mexichem, S. A. B. de C. V.), MFrisco (Minera Frisco, S. A. B. de C. V.), PEÑoles (Industrias Peñoles, S. A. B. de C. V.), Soriana (Organización Soriana, S. A. B. de C. V.), URBi (Urbi Desarrollos Urbanos, S. A. B. de C. V.).

5. IPC SmallCap. Incluye a las empresas más pequeñas en capitalización dentro de la muestra del Índice Compuesto.

Emisoras y empresas (16): AC (Arca Continental, S. A. B. de C. V.), ALSEA (Alsea, S. A. B. de C. V.), ARA (Consorcio Ara, S. A. B. de C. V.), Autlan (Compañía Minera Autlan, S. A. B. de C. V.), BACHOCO (Industrias Bachoco, S. A. B. de C. V.), COMERCi (Controladora Comercial Mexicana, S. A. B. de C. V.), gFamsa (Grupo Famsa, S. A. B. de C. V.), GMARTi (Grupo Martí, S. A. B. de C. V.), gruma (Gruma, S. A. B. de C. V.), Herdez (Grupo Herdez, S. A. B. de C. V.), KUO (Grupo KUO, S. A. B. de C. V.), MAXCOM (MAXCOM Telecomunicaciones, S. A. B. de C. V.), OMA (Grupo Aeroportuario del Centro Norte, S. A. B. de C. V.), SARE (Sare Holding, S. A. B. de C. V.), SIMEX (Grupo Simec, S. A. B. de C. V.), Vitro (Vitro, S. A. B. de C. V.).

6. Telecom MAXCOM. Este índice lo constituyen las series accionarias de empresas que pertenecen al sector económico de telecomunicaciones, considerando cualidades de representatividad y liquidez.

Emisoras y empresas (9): AMX (América Móvil, S. A. B. de C. V.), AXTEL (Axtel, S. A. B. de C. V.), Azteca (TV Azteca, S. A. B. de C. V.), CABle (Empresas Cablevisión, S. A. de C. V.), MAXCOM (Maxcom Telecomunicaciones, S. A. B. de C. V.), MEgA (Megacable Holdings, S. A. de C. V.), RCENTRO (Grupo Radio Centro, S. A. B. de C. V.), TelmeX (Teléfonos de México, S. A. B. de C. V.), TELEVISA (Grupo Televisa, S. A.).

7. Construye RT. Índice de actividad económica de rendimiento total que representa a los sectores de construcción e infraestructura, y lo constituyen las series accionarias con mayor representatividad y liquidez.

Emisoras y empresas (12): ARA (Consorcio Ara, S. A. B. de C. V.), CEMEX (Cemex, S. A. B. de C. V.), cisA (Carso Infraestructura y Construcción, S. A. B. de C. V.), CMoctez (Corporación Moctezuma, S. A. B. de C. V.), GCC (Grupo Cementos de Chihuahua, S. A. B. de C. V.), GEO (Corporación GEO, S. A. B. de C. V.), HomeX (Desarrolladora Homex, S. A. B. de C. V.), ICA (Empresas ICA, S. A. B. de C. V.), IDEAL (Impulsora del Desarrollo y el Empleo en América Latina, S. A. B. de C. V.), PINFRA (Promotora y Operadora de Infraestructura, S. A. B. de C. V.), SARE (Sare Holding, S. A. B. de C. V.), URBI (Urbi Desarrollos Urbanos, S. A. B. de C. V.). 
8. Comercio RT. Índice de actividad económica de rendimiento total que representa a los sectores de casas comerciales y distribuidoras, y lo constituyen las series accionarias con mayor representatividad y liquidez.

Emisoras y empresas (10): COMERCI (Controladora Comercial Mexicana, S. A. B. de C. V.), ElekTRA (Grupo Elektra, S. A. de C. V.), GCARso (Grupo Carso, S. A. B. de C. V.), GFamsa (Grupo Famsa, S. A. B. de C. V.), Gigante (Grupo Gigante, S. A. B. de C. V.), LAB (Genomma Lab Internacional, S. A. B. de C. V.), LiVepol (El Puerto de Liverpool, S. A. B. de C. V.), SORIANA (Organización Soriana, S. A. B. de C. V.), SPORT (Grupo Sports World, S. A. B. de C. V.), walmeX (Wal Mart de México, S. A. B. de C. V.).

9. Sector industrial. Grupo de series accionarias de las empresas pertenecientes al sector industrial.

Emisoras y empresas (29): ACCELSA (ACCEL, S. A. B. de C. V.), AEROMEX (Grupo Aeroméxico, S. A. B. de C. V.), ALfa (ALFA, S. A. B. de C. V.), ARA (Consorcio Ara, S. A. B. de C. V.), ASUR (Grupo Aeroportuario del Sureste, S. A. B. de C. V.), CERAMIC (Internacional de Cerámica, S. A. B. de C. V.), CICSA (Carso Infraestructura y Construcción, S. A. B. de C. V), DINE (DINE, S. A. B. de C. V.), GAP (Grupo Aeroportuario del Pacífico, S. A. B. de C. V.), GCARSO (Grupo Carso, S. A. B. de C. V.), GEO (Corporación GEO, S. A. B. de C. V.), GISSA (Grupo Industrial Saltillo, S. A. B. de C. V.), GMD (Grupo Mexicano de Desarrollo, S.A. B.), GMDR (GMD Resorts, S.A.B.), HOGAR (Consorcio Hogar, S. A. B. de C. V.), HOMEX (Desarrolladora Homex, S. A. B. de C. V.), ICA (Empresas ICA, S. A. B. de C. V.), IDEAL (Impulsora del Desarrollo y el Empleo en América Latina, S. A. B. de C. V.), INCARSO (Inmuebles Carso, S. A. B. de C. V.), KUO (Grupo KUO, S. A. B. de C. V.), lamosa (Grupo Lamosa, S. A. B. de C. V.), OHLmex (ohl México, S. A. B. de C. V.), OMA (Grupo Aeroportuario del Centro Norte, S. A. B. de C. V.), PASA (Promotora Ambiental, S. A. B. de C. V.), PINFrA (Promotora y Operadora de Infraestructura, S. A. B. de C. V.), PYP (Grupo Profesional Planeación y Proyectos, S. A. de C. V.), SARE (Sare Holding, S. A. B. de C. V.), TMM (Grupo TMM, S. A.), URBI (Urbi Desarrollos Urbanos, S. A. B. de C. V.).

10. Sector de servicios y bienes de consumo no básico. Grupo de series accionarias de las empresas pertenecientes al sector de bienes y servicios no básicos. Emisoras y empresas (20): ALSEA (Alsea, S. A. B. de C. V.), ARISTOS (Consorcio Aristos, S. A. de C. V.), CIDMEGA (Grupe, S. A. B. de C. V.), CIE (Corporación Interamericana de Entretenimiento, S. A. B. de C. V.), CMR (CMR, S. A. B. de C. V.), CNCI (Universidad CNCI, S. A. de C. V.), EDOARDO (Edoardos 
Martin, S. A. B de C. V.), Elektra (Grupo Elektra, S. A. de C. V.), GFAMSA (Grupo Famsa, S. A. B. de C. V.), GMARTI (Grupo Martí, S. A.B. de C. V.), GOMO (Grupo Comercial Gomo, S. A. de C. V.), GPH (Grupo Palacio de Hierro, S. A. B. de C. V.), hilasal (Hilasal Mexicana, S. A. B. de C. V.), IASASA (Industria Automotriz, S. A. de C. V.), LIVEPOL (El Puerto de Liverpool, S. A. B. de C. V.), Posadas (Grupo Posadas, S. A. B. de C. V.), REaltur (Real Turismo, S. A. de C. V.), SANLuis (San Luis Corporación, S. A. B. de C. V.), SPORT (Grupo Sports World, S. A. B. de C. V.), VASCONI (Grupo Vasconia, S. A. B.).

\section{REFERENCIAS BIBLIOGRÁFICAS}

Antón Sarabia, Arturo (2005). "Average Effective Tax Rates in Mexico", Economía Mexicana, Centro de Investigación y Docencia Económicas, vol. 14, núm. 2, pp. 185-215.

Arcelus, Francisco; Mitra, Devashis, y Srinivasan, Gopalan (2005). “On the Incidence of Deferred Taxes, Intangibles and Númn-Linearities in the Relationship between Tobin's Q and ROI", Journal of Econúmmics and Business, vol. 57, núm. 2, pp. 165-185.

Arrioja Vizcaíno, Adolfo (2001). Derecho fiscal, 15. a edición, Colección Textos Universitarios, México, Editorial Themis.

Banco de México (s.f.). "Estadísticas”, en Estadísticas. Consultado el 20 de julio de 2012 en http://www.banxico.gob.mx/estadisticas/index.html.

Bergman, Marcelo; Carreón Rodríguez, Víctor, y Hernández Trillo, Fausto (2005). "Evasión fiscal del Impuesto Sobre la Renta de personas morales", documento de trabajo, México, Centro de Investigación y Docencia Económicas, 84 pp.

Blouin, Jennifer; Gleason, Cristi; Mills, Lillian, y Sikes, Stephanie (2010). "Pre-Empting Disclosure? Firms' Decisions Prior to FIN 48”, The Accounting Review, vol. 85, núm. 3, pp. 791-815.

Cantalá, David; Sempere, Jaime, y Sobarzo, Horacio (2005). "Evasión fiscal en el Impuesto Sobre la Renta de personas físicas", documento de trabajo, El Colegio de México.

Carrasco Iriarte, Hugo (1997). Derecho fiscal constitucional, 3. a edición, Colección Textos Jurídicos Universitarios, México, Oxford University Press/Harla, México.

Cloyd, Bryan; Pratt, Jamie, y Stock, Toby (1996). "The Use of Financial Accounting Choice to Support Aggressive Tax Positions: Public and Private Firms", Journal of Accounting Research, vol. 34, núm. 1, pp. 23-43.

Chen, Kong Pin, y Chu, C. Y. Cyrus (2005). "Internal Control versus External Manipula- 
tion: A Model of Corporate Income Tax Evasion", RAND Journal of Economics, vol. 36, núm. 1, pp. 151-164.

Desai, Mihir (2003). "The Divergence between Book Income and Tax Income”, Tax Policy and the Economy, 17, pp. 169-206.

Desai, Mihir, y Dharmapala, Dhammika (2006). “Corporate Tax Avoidance and High Powered Incentives”, Journal of Financial Economics, vol. 79, núm. 1, pp. 145179.

- (2009). "Corporate Tax Avoidance and Firm Value", Review of Economics and Statistics, vol. 91, No. 3, pp. 537-546.

Diario Oficial de la Federación (1917, 5 de febrero). "Constitución Política de los Estados Unidos Mexicanos” (última reforma en DOF, 26 de febrero del 2013), México.

_ (1934, 4 de agosto). "Ley General de Sociedades Mercantiles" (última reforma en DOF, 2 de junio de 2009), México.

(1981, 31 de diciembre). "Código Fiscal de la Federación” (última reforma en DOF, 10 de mayo de 2011), México.

(2002, 1 de enero). "Ley del Impuesto Sobre la Renta" (última reforma en DOF, 31 de diciembre de 2010), México.

(2003, 17 de octubre). "Reglamento de la Ley del Impuesto Sobre la Renta" (última reforma en DOF, 4 de diciembre de 2006), México.

— (2010, 15 de noviembre). "Ley de Ingresos de la Federación para el Ejercicio Fiscal de 2011", México.

Díaz González, Eliseo, y Mendoza Cota, Jorge Eduardo (2005). "Evasión fiscal en el Impuesto Sobre la Renta: Retención de salarios", documento de trabajo, México, El Colegio de la Frontera Norte.

Dyreng, Scott, Hanlon, Michelle, y Maydew, Edward (2008). "Long-run corporate tax avoidance", The Accounting Review, vol. 83, núm. 1, pp. 61-82.

Financial Accounting Standards Board (1992). Statement of Financial Accounting Standards No. 109, Connecticut, FASB.

Financial Accounting Standards Board (2006). Accounting for Uncertainty in Income Taxes, Connecticut, FASB.

Graham, John R., y Tucker, Alan L. (2006). "Tax Shelters and Corporate Debt Policy", Journal of Financial Economics, núm. 81, pp. 563-594.

Gupta, Sanjay, y Newberry, Kaye (1997). "Determinants of the Variability in Corporate Effective Tax Rates: Evidence from Longitudinal Data", Journal of Accounting and Public Policy, núm. 16, pp. 1-34.

Hanlon, Michelle (2005). "The Persistence and Pricing of Earnings, Accruals, and Cash 
Flows When Firms Have Large Book-Tax Differences", The Accounting Review, vol. 80, núm. 1, pp. 137-166.

Hanlon, Michelle, y Heitzman, Shane (2010). “A Review of Tax Research", Journal of Accounting and Economics, vol. 50, núms. 2-3, pp. 127-178.

Hanlon, Michelle, y Slemrod, Joel (2009). "What does Tax Aggressiveness Signal? Evidence from Stock Price Reactions to News about Tax Shelter Involvement", Journal of Public Economics, vol. 93, núms. 1-2, pp. 126-141.

Instituto Nacional de Estadística y Geografía (s.f.). "Estadística", en Instituto Nacional de Estadística y Geografía (INEGI). Consultado el 20 de julio de 2012 en http:// www.inegi.org.mx/est/contenidos/proyectos/estadistica/default.aspx.

Krull, Linda (2004). "Permanently Reinvested Foreign Earnings, Taxes, and Earnings Management”, The Accounting Review, vol. 79, núm. 3, pp. 745-767.

Miller, Gregory S., y Skinner, Douglas J. (1998). "Determinants of the Valuation Allowance for Deferred Tax Asset under SFAS No. 109", The Accounting Review, vol. 73, núm. 2, pp. 213-233.

Mills, Lillian (1998). "Book-Tax Differences and Internal Revenue Service Adjustments", Journal of Accounting Research, vol. 36, núm. 2, pp. 343-356.

Mills, Lillian, y Newberry, Kaye (2001). "The Influence of Tax and Non-Tax Costs on Book-Tax Reporting Differences: Public and Private Firms", The Journal of the American Taxation Association, vol. 23, núm. 1, pp. 1-19.

OECD (s.f.). "OECD Data Lab”, en Statistics-Organisation for Economic Co-operation and Development. Consultado el 20 de julio de 2012 en http://www.oecd.org/ statistics/.

OCDE (2009). La administración tributaria en los países de la OCDE y en determinados países no miembros, Serie Información comparada 2008, España, Centro de Política y Administración Tributaria, Organización para la Cooperación y el Desarrollo Económicos.

Phillips, John; Pincus, Morton, y Olhoft-Rego, Sonja (2003). "Earnings Management: New Evidence Based on Deferred Tax Expense", The Accounting Review, vol. 78, núm. 2, pp. 491-521.

Plesko, George (2003). “An Evaluation of Alternative Measures of Corporate Tax Rates", Journal of Accounting and Economics, vol. 35, núm. 2, pp. 201-226.

Revilla, Eduardo y Zamudio, Andrés (2001). "Reforma fiscal y distribución de la carga impositiva en México", documento de trabajo, México, Centro de Investigación y Docencia Económicas.

Samaniego Breach, Ricardo; Endo Martínez, Anabel Mitsuko; Mendoza Montenegro, Vidal, y Zorrilla Mateos, Francisco Marcos (2006). Medición de la evasión fis- 
cal en México, México, Centro de Economía Aplicada y Políticas Públicas, ITAM.

SAT (2010). Régimen general. Guía para presentar por Internet la declaración anual del 2010 con el programa DEM. Personas morales, México, Servicio de Administración Tributaria, Secretaría de Hacienda y Crédito Público.

Servicio de Administración Tributaria (s.f.). "Legislación y normatividad", en Legislación y normatividad - 2013. Consultado el 2 de mayo de 2013 en http://www. sat.gob.mx/sitio_internet/informacion_fiscal/legislacion/default.asp.

SHCP (2007). Plan Estratégico 2007-2012, 2. a edición, México, Secretaría de Hacienda y Crédito Público, Servicio de Administración Tributaria.

— (2010 a). Distribución del pago de impuestos y recepción del gasto público por deciles de hogares y personas. Resultados para el año 2008, México, Secretaría de Hacienda y Crédito Público, p. 2.

(2010b). Presupuesto de Gastos Fiscales 2010, México, Secretaría de Hacienda y Crédito Público.

(2011). El Impuesto Empresarial a Tasa Única (IETU): un diagnóstico a tres años de su implementación, México, Secretaría de Hacienda y Crédito Público.

(s.f.). "Estadísticas oportunas de finanzas públicas", en Finanzas públicas. Consultado el 20 de julio de 2012 en http://www.shcp.gob.mx/POLITICAFINANCIERA/FINANZASPUBLICAS/Estadísticas_Oportunas_Finanzas_Publicas/ Informacion_mensual/Paginas/finanzas_publicas.aspx.

Stickney, Clyde P. y Victor, E. McGee (1982). "Effective Corporate Tax Rates - The Effect of Size, Capital Intensity, Leverage, and other Factors", Journal of Accounting and Public Policy, núm. 1, pp. 125-152.

Venegas Álvarez, Sonia (2011). Derecho fiscal, $1^{\text {a }}$ reimpresión, México, Oxford University Press.

Whitaker, Celia (2005). "Bridging the Book-Tax Accounting Gap", The Yale Law Journal, vol. 115, núm. 3, pp. 680-726. 